Florida International University FIU Digital Commons

4-4-1997

\title{
Elder malnutrition: A meta analysis of studies using the nutrition screening initiative determine checklist
}

Carmen Teresa Brain Urrunaga

Florida International University

DOI: $10.25148 /$ etd.FI14051821

Follow this and additional works at: https://digitalcommons.fiu.edu/etd

Part of the Dietetics and Clinical Nutrition Commons

\section{Recommended Citation}

Brain Urrunaga, Carmen Teresa, "Elder malnutrition: A meta analysis of studies using the nutrition screening initiative determine checklist" (1997). FIU Electronic Theses and Dissertations. 1786.

https://digitalcommons.fiu.edu/etd/1786 


\title{
FLORIDA INTERNATIONAL UNIVERSITY \\ Miami, Florida
}

ELDER MALNUTRITION: A META ANALYSIS OF STUDIES USING THE NUTRITION SCREENING INITIATIVE DETERMINE CHECKLIST

\author{
A thesis submitted in partial satisfaction of the \\ requirements for the degree of \\ MASTER OF SCIENCE \\ IN \\ DIETETICS AND NUTRITION \\ by \\ Carmen Teresa Brain Urrunaga
}


To: Judith A. Blucker, Dean

College of Health

This thesis, written by Carmen Teresa Brain Urrunaga, and entitled ELDER MALNUTRITION: A META ANALYSIS OF STUDIES USING THE NUTRITION SCREENING INITIATIVE DETERMINE CHECKLIST, having been approved in respect to style and intellectual content, is referred to you for judgment.

We have read this thesis and recommend that it be approved.

Dr. Chockalingam Viswesvaran

Dr. Dian O. Weddle

Dr. Nancy S. Wellman, Major Professor

Date of Defense: April 4, 1997

The thesis of Carmen Teresa Brain Urrunaga is approved.

Dean Judith A. Blucker

College of Health

Dr. Richard L. Campbell

Dean of Graduate Studies 
I dedicate this thesis to the memory of my mother, Kathy.

Her strength, wisdom, and love will live within me always. 


\section{ACKNOWLEDGMENTS}

I wish to thank the members of my committee, and especially my major professor, for their time, direction, and support throughout this project. My father also deserves special recognition for statistical guidance and the program design he has given me.

I also want to thank my husband, Sergio, and my parents for their support, patience, and most of all love, without which the completion of this work, and my degree, would not have been possible. 


\title{
ABSTRACT OF THE THESIS \\ ELDER MALNUTRITION: A META ANALYSIS OF STUDIES USING THE NUTRITION SCREENING INITIATIVE DETERMINE CHECKLIST
}

\author{
by \\ Carmen Teresa Brain Urrunaga \\ Florida International University, 1997 \\ Miami, Florida \\ Professor Nancy S. Wellman, Major Professor
}

To demonstrate the extent of elder malnutrition risk in this country, a meta analysis of 30 studies that used the Nutrition Screening Initiative's "DETERMINE Your Nutritional Health Checklist" was conducted. The studies were divided into three categories: Elder Populations in Healthcare Related Systems (HS), Elder Meal Program Participants (MP), and General Community Residing Elder Population (GC). HS was sub-divided into Hospital Inpatient/Clinic Outpatient and Long Term Care/Home Care. The MP population were identified as Congregate or Home Delivered meal participants. Overall, results indicate that $63 \%$ of elders are at moderate $(32 \%)$ or high $(31 \%)$ risk of malnutrition. Home Delivered Meal Participants and Hospital Inpatient/Clinic Outpatients are most likely to be at high risk of malnutrition ( $49.5 \%$ and $49.1 \%$, respectively). 
Individuals least likely to be at high malnutrition risk are the General Community Residing Elder Population (17.5\%) and Congregate Meal Participants (22.5\%). 


\section{TABLE OF CONTENTS}

Chapter

I. Introduction

II. Review of Literature 5

Nutrition Screening Initiative $\quad 5$

NSI Checklist Development

NSI Checklist Questions and Interventions $\quad 10$

Review of Studies Included in the Meta Analysis 14

Elder Populations in Healthcare Related Systems $\quad 15$

Elder Meal Program Participants 23

General Community Residing Elder Population 28

Elderly Nutrition Program Evaluation 31

Nutrition Indicators and Assessments 33

Anthropometrics 33

Biochemical Parameters $\quad 34$

Meta Analysis $\quad 36$

III. Methodology 38

Data Collection 38

Data Organization $\quad 40$

Statistical Analysis $\quad 41$

IV. Results $\quad 45$

V. Discussion $\quad 55$

Assumptions and Limitations $\quad 55$

Extent of Elder Malnutrition $\quad 56$

IV. Summary, Conclusions, and Recommendations 59

List of References $\quad 65$

$\begin{array}{ll}\text { Appendices } & 72\end{array}$ 


\section{LIST OF TABLES}

Table

Page

1.1: Elder Populations In Healthcare Related Systems - NSI Checklist Screening Findings

1.2: Elder Meal Program Participants - NSI Checklist Screening

Findings

1.3: General Community Residing Elder Population - NSI Checklist Screening Finding

2: Percentage Of Affirmative Responses To NSI DETERMINE Your Nutritional Health Checklist Statements

3.1: Individuals At High Nutritional Risk ( $80 \%$ Confidence Interval)

3.2: Individuals At Moderate Nutritional Risk ( $80 \%$ Confidence Interval)

3.3: Individuals At Low Nutritional Risk ( $80 \%$ Confidence Interval)

4.1: High Nutritional Risk: Statistically Significant Differences Between Categories

4.2: Low Nutritional Risk: Statistically Significant Differences Between Categories

5.1: Positive Predictive Values And Validity Coefficients Of Studies Using Level I Screen

6: Positive Predictive Value And Validity Coefficient Of Study Using Level II Screen 


\section{Chapter I}

\section{Introduction}

Nutrition screening is defined by the national Nutrition Screening Initiative as the "process of identifying characteristics known to be associated with dietary or nutritional problems. Its purpose is to differentiate individuals who are at high risk of nutritional problems or who have poor nutritional status" (1). Nutrition screening for individuals over the age of 65 has become increasingly important, especially as the elderly population in this country not only continues to grow so rapidly, but also becomes older itself. With the rising costs of health care, nutrition screening can serve as an opportunity to practice prevention, therefore delaying hospital and nursing home admission, and saving money. Older Americans experience a variety of nutritional problems and needs related to the processes of aging; inappropriate dietary intakes and chronic disease place a substantial number of older adults at high risk of malnutrition (1).

Screening is the first step toward intervention in preventing nutritionrelated health problems and a decline in nutritional status. The Nutrition Screening Initiative (NSI) has produced a ten-item nutrition screening tool for elders called the DETERMINE Your Nutritional Health Checklist (NSI Checklist) (Appendix A). Throughout the country, several researchers, health professionals, and State Offices on Aging have used this NSI Checklist, or a modified form of it, as the primary data collection instrument in determining the incidence of elder malnutrition risk in specific populations. A meta analysis of these studies is 
warranted to aggregate the various findings, and to identify trends in elder malnutrition risk. Meta analysis is the chosen method because it is unusual for "single experiments or studies [to] provide sufficiently definitive answers upon which to base policy" (2). The purpose of this meta analysis is to obtain an overall view of elder malnutrition risk across the United States and to determine the variability of risk among elder population groups. Additionally, a test for validity, based on results of Level I or II Screens following the NSI Checklist, was executed to ascertain whether or not the instrument is correctly identifying those elders at risk for malnutrition.

The NSI has also devised Level I and Level II Screens (Appendix A), which are instruments to be used by social service and/or health professionals to follow up on individuals with NSI Checklist scores indicating moderate or high risk for malnutrition. The Level I Screen provides a clear and uncomplicated way to distinguish those elders who need to be referred for further evaluation and possible interventions including medical or other social services. The Level II Screen should be completed with a physician or other health care provider as it calls for laboratory values and mental status evaluations. These screens serve to identify elders with nutritional problems or medical conditions that can negatively influence their nutritional health (1). Many of the items on the Level I Screen are repeated on the Level II Screen as the Level II Screen does not necessarily follow the Level I Screen, but can be used in its stead. It may be appropriate to skip the Level I Screen for individuals who score very high on the NSI Checklist because the Level II Screen includes more precise diagnostic measurements. 
It is not uncommon for nutrition screening to be done only when the individual is already ill, malnourished or has been admitted to a hospital or longterm care facility. The more common screening measures used at this time are anthropometric measurements (such as height, weight, triceps skinfold, mid-arm circumference, and mid-arm muscle circumference), subsequent calculation of body mass index and percent of ideal body weight, and biochemical parameters (such as serum albumin and serum cholesterol). A great number of studies have been completed using these and other measurements to determine malnutrition and consequent morbidity and/or mortality in elderly persons. Unfortunately, these measurements show only the presence (or lack) of malnutrition at a specific point in time, not the risk of developing malnutrition.

The purpose of this investigation was to conduct a meta analysis of studies using the Nutrition Screening Initiative Checklist to determine elder malnutrition risk. To this purpose, the following hypotheses will be tested:

1. The meta analysis of studies using the Nutrition Screening Initiative Checklist to determine malnutrition risk will show that over one-half of the elder population is at moderate to high risk for malnutrition.

2. The meta analysis of studies using the Nutrition Screening Initiative Checklist to determine malnutrition risk will show that there will be differences in malnutrition risk across elder populations (i.e., meal program participants, community residing elders, institutionalized elders).

3. The Nutrition Screening Initiative Checklist is a valid screening instrument for determining elder malnutrition risk in community residing elders and meal 
program participants, based on positive predictive values determined from those studies using Level I and/or Level II Screens. 


\section{Chapter II}

\section{Review Of Literature}

\section{Nutrition Screening Initiative}

The Nutrition Screening Initiative (NSI) was formed in 1990 by a joint effort of the American Academy of Family Physicians, the American Dietetic Association, and the National Council on the Aging. It was developed because these three groups felt that nutritional status should become a "vital sign" in the delivery of health care in the United States $(1,3)$. The NSl's creation was in direct response to the calls for increased nutrition screening by the 1988 Surgeon General's Workshop on Health Promotion and Aging as well as the United States Department of Health and Human Services report entitled "Healthy People 2000." The NSI believes that better nutritional care can lead to better health and to better outcomes with respect to health and quality of life when people are ill or injured $(1,3,4)$.

NSI Checklist Development

It took over two years for the NSI to develop the DETERMINE Your Nutritional Health Checklist. The first task the NSI had to complete was a comprehensive literature review of the prevalence of nutrition-related problems and current approaches to screening $(1,4)$. At a national consensus conference, and after an extensive search and review, an agreement was reached on the seven categories of risk factors and indicators of poor nutritional status in older 
Americans (3). The definition of poor nutritional status includes deficiency, dehydration, undernutrition, nutritional imbalances, obesity, alcohol abuse, inappropriate dietary intakes for diseases or conditions that have nutritional implications, and evidence that nutritional status is deteriorating over time (1). The NSI defines risk factors of poor nutritional status as characteristics that are associated with an increased likelihood of poor nutritional status. They include: the presence of various acute or chronic diseases and conditions, inadequate or inappropriate food intake, poverty, dependency/disability, and chronic medication use (1). Indicators of poor nutritional status are "generally quantitative and provide evidence that poor nutritional status is present. Indicators include dietary, clinical, anthropometric, and biochemical parameters as well as the existence of nutrition-related conditions or diseases" $(1,4)$.

An agreement was needed regarding the degree of importance each factor was to be given, and the degree and manner in which they should be assessed. It was only after several revisions that the DETERMINE Your Nutritional Health Checklist was finalized. The NSI Checklist incorporates all of the identified risk factors and indicators of poor nutritional status. It is arranged in a format of ten statements, each of which is assigned a number of points.

Prior to widespread distribution, the NSI Checklist was tested. Focus groups of older Americans reviewed and critiqued it. Their suggestions led to alterations in the NSl's Checklist length, format, educational level, and style of presentation (5). Then retrospective simulation and prospective validation 
techniques were used to test the ability of the NSI Checklist to predict nutritionrelated problems of older Americans (6).

The purposes of the NSI Checklist are twofold, to provide basic nutrition information to people regarding characteristics that may increase the likelihood of poor nutritional status and to guide consumers to begin a dialogue with their health and social services providers about personal nutrition concerns (5). It is not intended to be used as a diagnostic tool, but has been found to be a valid and reliable measure of potential nutritional risk $(5,7)$.

The NSI Checklist is very simple to use, as it was primarily meant to be put to use in the community. It is written at a fourth- to sixth-grade reading level for easy use by older Americans, their family members and caregivers. On the front, there is a set of basic statements addressing the general categories of nutritional risk as defined by the $\mathrm{NSI}(1,7)$. Every time a statement is responded to affirmatively, an assigned number of points is accumulated. Once the entire NSI Checklist is completed, the total number of points is tallied to arrive at what is called a total nutritional score. There is an explanation of possible total nutritional scores on the NSI Checklist, making it easy for most individuals to interpret the results (Appendix A). A total score of 0-2 indicates low risk; 3-5 moderate risk; and $\geq 6$ indicates high risk for malnutrition (8). 


\section{Total your nutritional score. If it's -}

0-2 Good! Recheck your nutritional score in 6 months.

3 - $5 \quad$ You are at moderate risk. See what can be done to improve your eating habits and lifestyle. Your office on aging, senior nutrition program, senior citizens center or health department can help. Recheck your nutritional score in 3 months.

6 or more You are at high nutritional risk. Bring this checklist the next time you see your doctor, dietitian or other qualified health or social service professional. Talk with them about any problems you may have. Ask for help to improve your nutritional health (8).

The NSI Checklist is not meant as an "endpoint of nutrition screening and assessment, but the beginning of an ongoing process" (7).

On the back of the NSI Checklist, basic nutrition information is conveyed using the word DETERMINE as a mnemonic device. For each letter of the word DETERMINE, a risk factor is cited with a brief paragraph describing the key elements of increased nutritional risk related to that characteristic $(5,7)$. As previously stated, the NSI Checklist was developed primarily for the public awareness campaign. Thus it was designed to be simple enough to be selfadministered.

The Level I and II Screens were designed for individuals who have NSI Checklist scores indicating moderate and high risk for malnutrition. The Level I and II Screens expand on the identification of risk factors from the NSI Checklist to include major and minor indicators. Minor indicators include dehydration, alcoholism, poorly healing wounds, nutrient deficiencies, apathy, fatigue, and 
cognitive impairment. Major indicators are more quantifiable and include serum albumin below $3.5 \mathrm{gm} / \mathrm{dl}$, triceps skinfold below the $10^{\text {th }}$ percentile or above the $95^{\text {th }}$ percentile, weight loss of 10 pounds or more, change in functional status, inappropriate food intake, obesity, and nutrition-related disorders $(1,9)$.

The Level I Screen can be quickly and easily completed by a social service or health professional with no special equipment or laboratory data necessary. This screen serves to identify those elder individuals to be referred for further evaluation as well as those who may benefit from medical and social services. For example, people who have experienced notable involuntary weight change are categorized at high risk and should be immediately referred to a physician or dietitian $(5,7)$. Individuals without quantifiable clinical nutrition deficiencies but who possess a number of factors that impair their ability to obtain a reasonable and nutritious diet (e.g., limited economic resources) are often at moderate risk and may benefit from referrals to community-based programs (5). These referrals include, but are not limited to, dietitians, psychologists, dentists, the Food Stamp Program, transportation services, homemaker and chore services, adult day care services, and home delivered and congregate meal programs (9).

The Level II Screen may follow the Level I Screen, or may be used in its place. It is intended to be completed by a health professional in a clinical setting. It aims to identify elders with potentially serious medical or nutritional problems, including malnutrition. "The goal is to identify these problems early on and to intervene, when possible, before health and quality of life are seriously impaired 
or survival is threatened, and when return to or stabilization of nutritional health is a realistic objective" (5).

The Level II Screen is the most comprehensive of the NSI tools and includes some of the same factors assessed in Level I, adding more specific diagnostic elements such as anthropometric measurements, clinical signs of nutrient deficiency, laboratory tests, functional status assessment, chronic medication use, living environment, and cognitive and emotional status assessments (5). The Level II Screen can assist in the identification of individuals with protein-calorie malnutrition, obesity, hyperlipidemia, and osteoporosis (5).

In 1992, an Interventions Roundtable of 30 individuals from the disciplines of medicine, health, nutrition, dentistry, pharmacology, mental health, and social services met to specify interventions appropriate to findings from the NSI Checklist or Level I or II Screens. Consensus was achieved on recommendations for interventions in the six areas of social services, oral health, mental health, medication use, nutrition education and counseling, and nutrition support (4).

NSI Checklist Questions and Interventions

Each of the ten statements on the NSI Checklist has interventions associated with it. The first statement is, "I have an illness or condition that made me change the kind and/or amount of food I eat." This statement is worth two points and is linked with interventions in nutrition education and counseling and 
nutrition support. Many elders are confused about medical nutrition therapies for chronic and acute diseases and complications. Solutions require a detailed knowledge of food as well as the physiological modifications dictated by disease (9). Nutrition counseling should be done by someone with dietetics and nutritional expertise (10). This is usually provided most cost-effectively by registered dietitians.

The second statement reads, "I eat fewer than 2 meals per day" and is worth three points. It is linked to interventions of social services and nutrition education and counseling. Individuals may be referred to meal programs or congregate feeding centers to address poor dietary intakes due to social isolation. Other social service interventions include food stamps or food distribution programs to ease poverty-related undernutrition $(9,10)$.

Statement number three is, "I eat few fruits or vegetables, or milk products." This statement is associated with interventions in nutrition education and counseling and nutrition support and is worth two points. Some elders have misconceptions about the effects of certain foods, and the resulting self-imposed diets may limit their intake of nutrient-dense foods in "well-meaning but misguided attempts to improve health" (10).

Statement number four reads, "I have 3 or more drinks of beer, liquor or wine almost every day." It is worth two points and linked to nutrition education and counseling, mental health, and medication use. Some elders who are lonely or depressed may turn to alcohol to feel better (9). Alcohol consumption may be replacing more nutrient dense foods or may lead to dangerous drug interactions. 
Nutrition education and counseling as well as mental health and medication use counseling may help to prevent a decline in nutrition and health status.

Number five is, "I have tooth or mouth problems that make it hard for me to eat" and is worth two points. It is linked to oral health, nutrition education and counseling, and nutrition support interventions. If an eating difficulty is identified, diet modification and/or consultation with the appropriate dental health professional are reasonable interventions that can do much to improve nutritional outcomes (10).

Statement number six is worth the most points, four. It is, "I don't always have enough money to buy the food I need." This statement is linked to social services' interventions that include food stamps or food distribution programs to ease poverty-related undernutrition (10). Poverty is one of the most important risk factors leading to malnutrition in older Americans, and social services interventions may help individuals to achieve their "highest level of functioning by addressing social, health, and welfare needs" (9).

Number seven reads, "I eat alone most of the time." It, and also statement eight, is worth the least amount of points, one. Statement seven is associated with interventions including social services and mental health. The loss of a spouse can often dramatically affect the survivor's eating habits. Individuals may be depressed due to loss of functional ability or independence. Referring these elders to a counselor as well as to meal programs or congregate feeding centers will start to address poor dietary intakes due to social isolation $(9,10)$. 
Statement number eight, "I take 3 or more different prescribed or over-thecounter drugs a day" is worth one point and is linked to medication use interventions. "Medications can affect nutrient needs and alter metabolic responses to foods and [other] drugs" (10). Interventions may include education on adverse reactions to drugs, drug/nutrient interactions, and drug/drug interactions (9).

Statement number nine is, "Without wanting to, I have lost or gained 10 pounds in the last 6 months." It is worth two points and is linked to inventions in nutrition education and counseling, nutrition support, and medication use.

Nutritional problems can be medically and psychosocially complex. Appropriate interventions can range from education or counseling sessions to supplementation to alternate feeding routes in extreme cases (9). "Decisions to provide palliative nutrition regimens or to withhold or withdraw nutrition support must also be made in some circumstances" (10).

Finally, statement number ten reads, "I am not always physically able to shop, cook and/or feed myself." It is also worth two points. It is associated with the interventions in social services and nutrition support. These services may include transportation or homemaker services to decrease the impact functional impairment can have on food consumption. Also, there are a variety of products and technologies available to make feeding easier $(9,10)$.

A number of researchers have used the NSI Checklist and Level I and II Screens in hospitals, nursing facilities, meal programs, and community settings as a way to determine the incidence of malnutrition among elders. A meta 
analysis of these studies would provide a better estimation of elder malnutrition risk across the country.

\section{Review of Studies Included in the Meta Analysis}

Thirty studies were included in the meta analysis. They were found as a result of an exhaustive literature search. Additionally, some of the studies were found through personal communications resulting from a newsletter announcement, a search in the "success stories" portion of "Implementing Nutrition Screening and Intervention Strategies," (4) and from requests for reports of state nutrition surveys for the 1995 State Nutritionist Meeting (see Methodology section). All of the authors were contacted by telephone, fax, and/or mail to obtain some data that was not necessarily reported in their study, but was needed for the meta analysis. This procedure is described in more detail in the chapter entitled Methodology.

The 30 studies were divided into three categories depending on the populations surveyed. The categories are: Elder Populations in Healthcare Related Systems (HS), Elder Meal Program Participants (MP), and General Community Residing Elder Population (GC). The HS category was then subdivided into Hospital Inpatient and Clinic Outpatient (HICO) and Long Term Care and Home Care (LTCHC) (Table 1.1). Similarly, the MP category was subdivided into Congregate Meal Participants (C) and Home Delivered Meal Participants (HD) (Table 1.2). The GC category was not sub-divided (Table 1.3). 


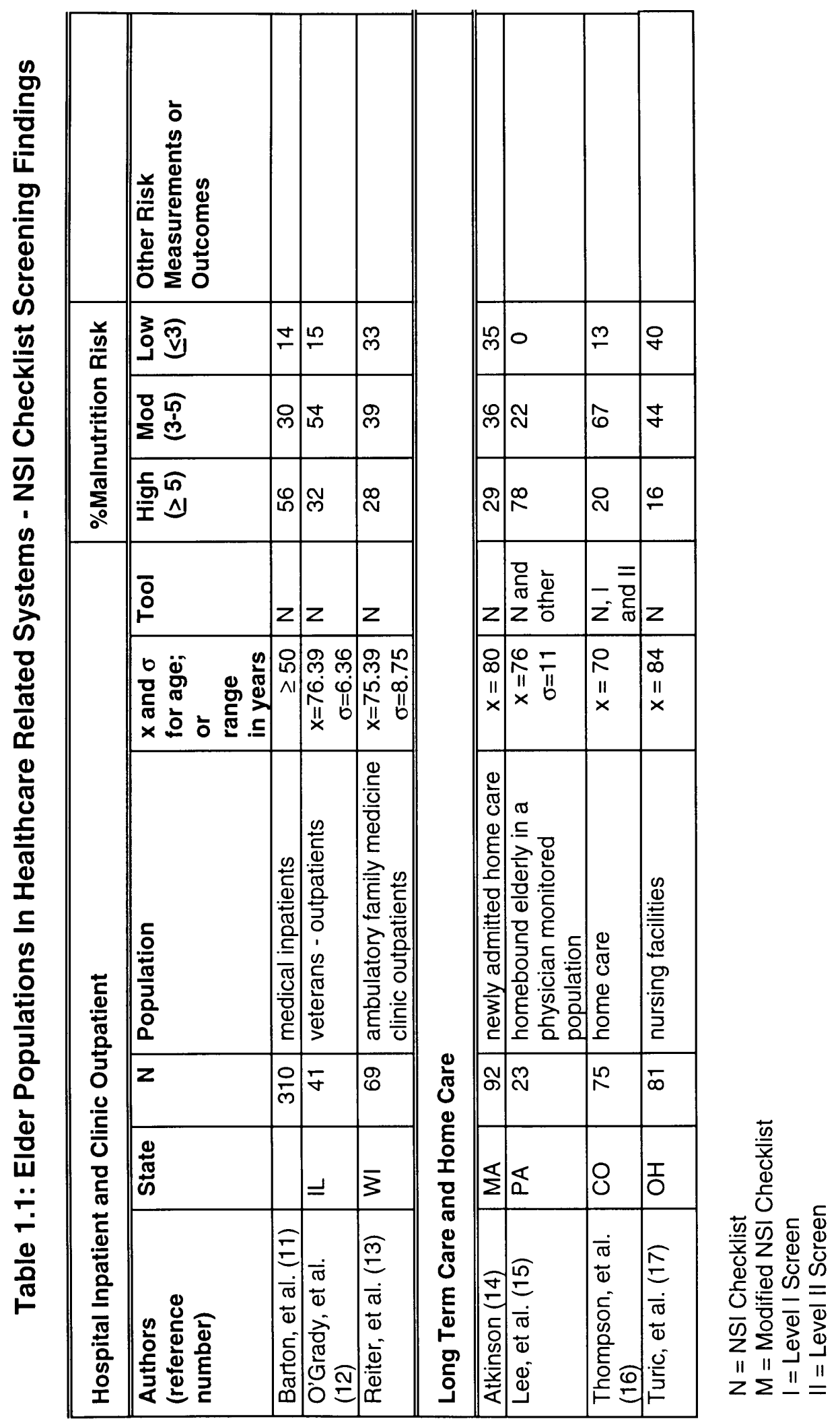




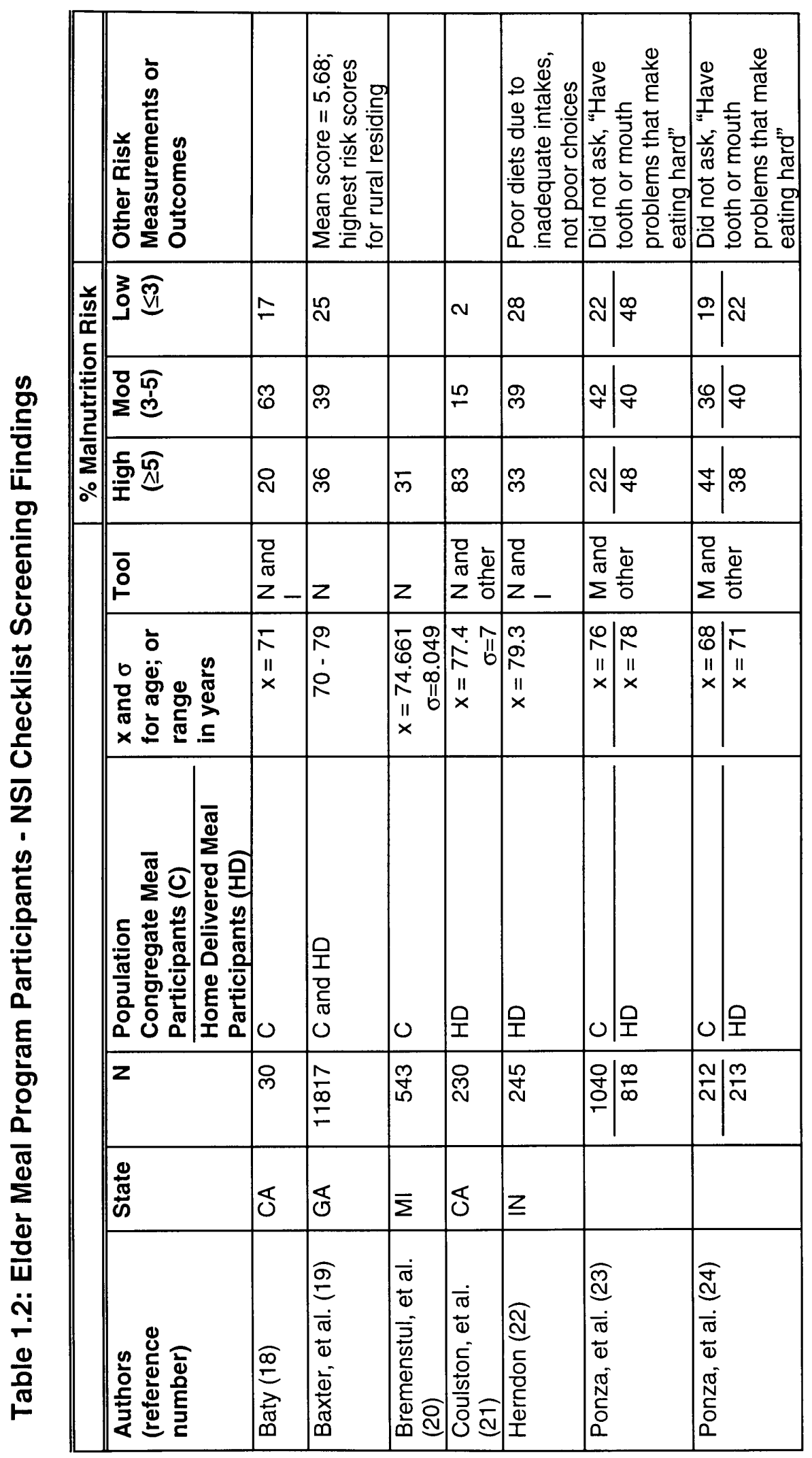




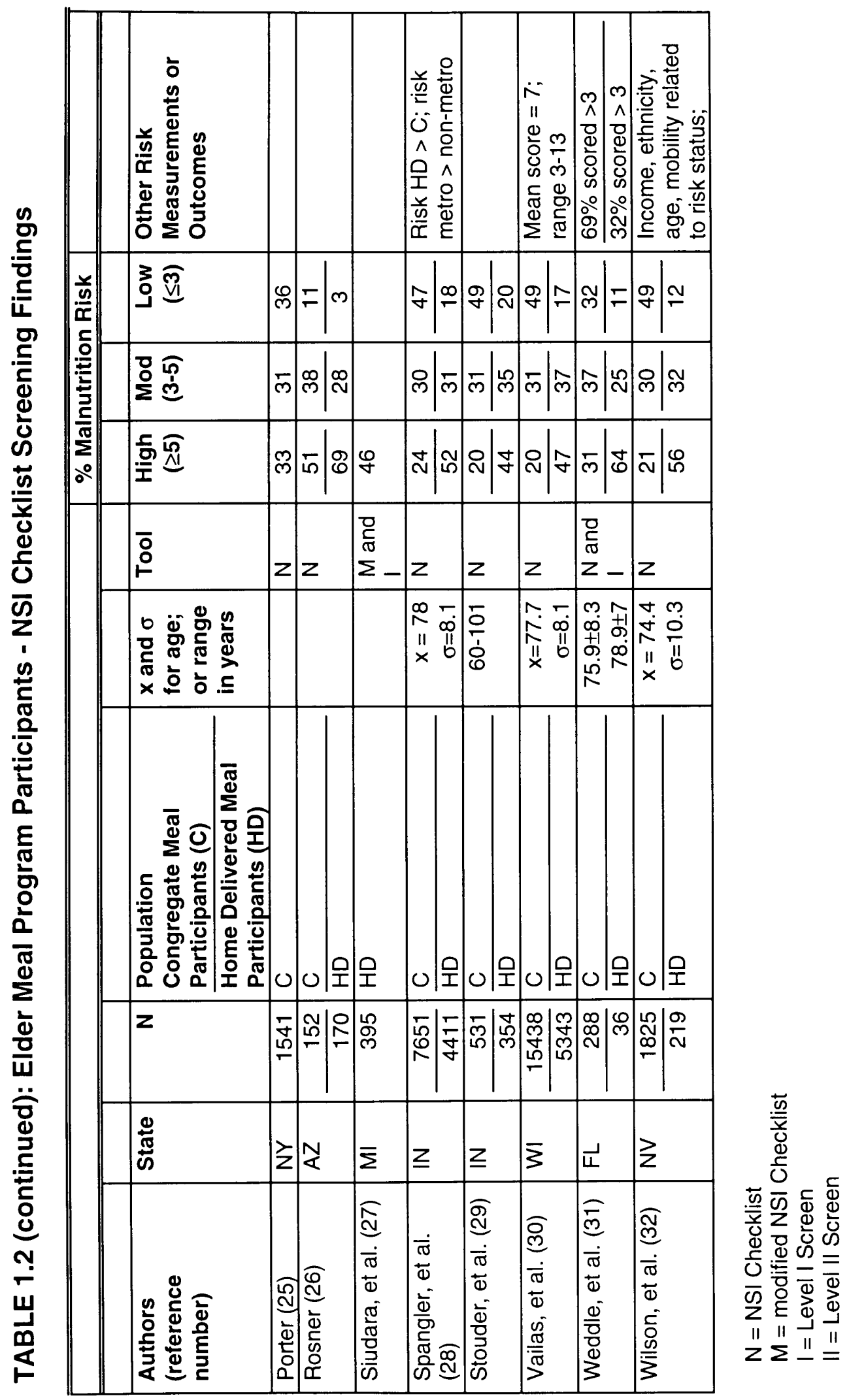




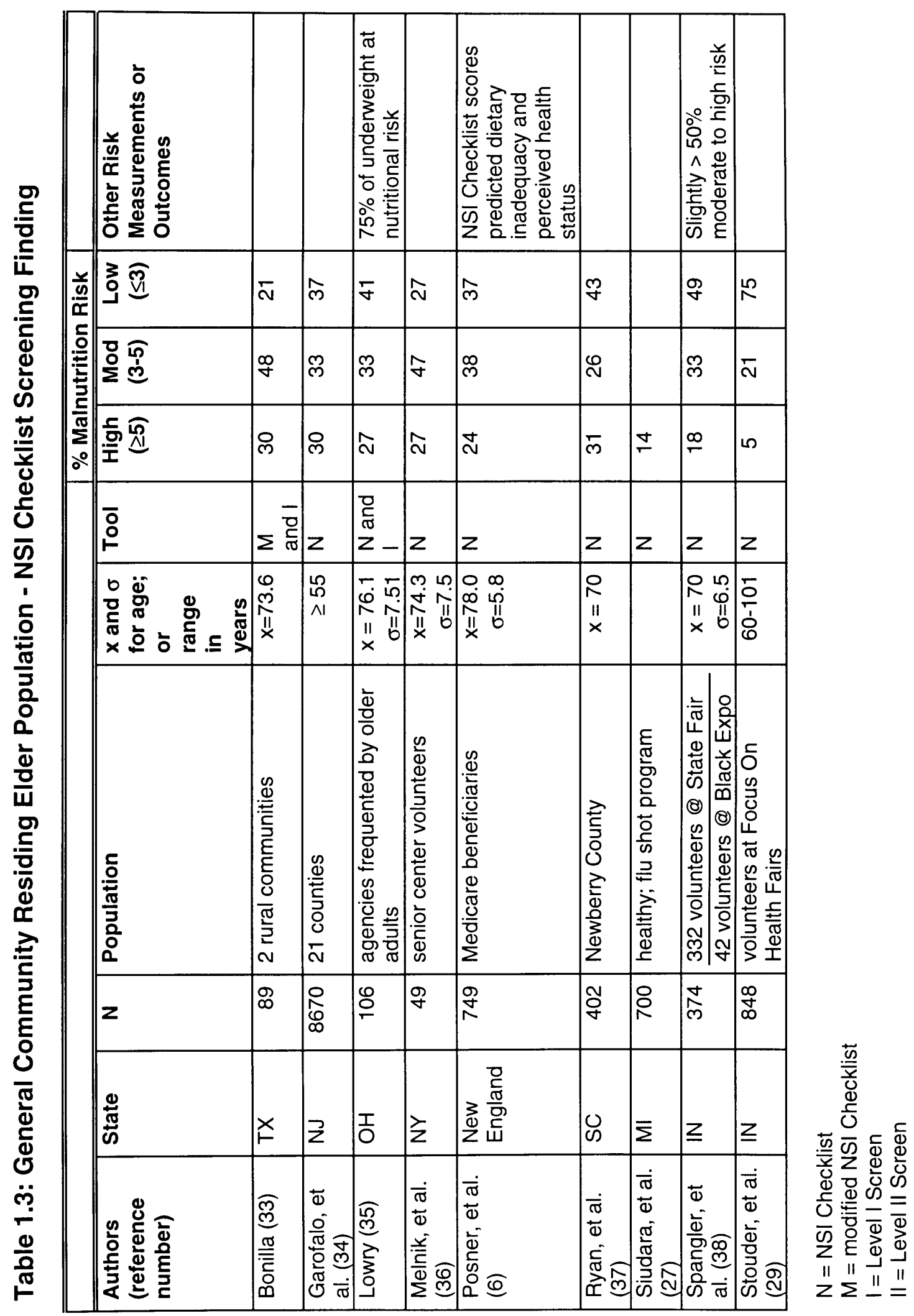


Some of the additional data the authors were requested to provide was the percentage of individuals answering affirmatively to each statement on the NSI Checklist. This data can be seen in Table 2.

Elder Populations in Healthcare Related Systems

Barton, et al., assessed 310 hospitalized patients aged 50 years and older using the NSI Checklist, albumin and prealbumin levels (11). Data were collected within 24 hours of admission. Results show that prealbumin levels, gender, and age were statistically related to NSI risk categories $(p<.002)$; however, albumin was not. The authors state that "the predictive validity of the NSI is explored using serum proteins thought to indicate levels of nutritional comprise."

Furthermore, they conclude that the prealbumin biomarker "may be indicative of the acute nature of illness among newly hospitalized patients, whereas albumin may be indicative of more chronic conditions" (11).

O'Grady, et al., assessed 41 elderly veterans who visited VA Hines Hospital Geriatric Outpatient Clinic using the NSI Checklist (12). The purpose of the project was twofold: to ascertain the percentage of patients at good, moderate or high nutritional risk as determined by the NSI Checklist, and to determine what percentage of patients scoring "high" were referred to the dietitian for counseling. Of the 13 patients who received a score of "high," $77 \%$ were referred to the dietitian. The researchers concluded that the NSI Checklist "was an efficient and valuable tool for assessing the nutritional status of the 
Table 2: Percentage Of Affirmative Responses To NSI DETERMINE Your Nutritional Health Checklist Statements

\begin{tabular}{|l|r|r|r|r|r|r|r|r|r|r|}
\hline $\begin{array}{l}\text { Authors } \\
\text { (reference number) }\end{array}$ & \multicolumn{7}{|c|}{ NSI Checklist Statement Number } \\
\hline Hospital Inpatient and Clinic Outpatient & $\mathbf{1}$ & $\mathbf{2}$ & $\mathbf{3}$ & $\mathbf{4}$ & $\mathbf{5}$ & $\mathbf{6}$ & $\mathbf{7}$ & $\mathbf{8}$ & $\mathbf{9}$ & $\mathbf{1 0}$ \\
\hline Barton, et al. (11) & & & & & & & & & & \\
\hline O'Grady, et al. (12) & 56 & 5 & 22 & 5 & 22 & 7 & 37 & 61 & 27 & 34 \\
\hline Reiter, et al. (13) & 42 & 10 & 35 & 6 & 15 & 4 & 36 & 44 & 25 & 20 \\
\hline \hline
\end{tabular}

\section{Long Term Care and Home Care}

\begin{tabular}{|c|c|c|c|c|c|c|c|c|c|c|}
\hline Atkinson (14) & 22 & 12 & 20 & 1 & 19 & $\overline{7} 7$ & 41 & 42 & 28 & 47 \\
\hline \multicolumn{11}{|l|}{ Lee, et al. (15) } \\
\hline Thompson, et al. (16) & 16 & 2 & 44 & 5 & 13 & 2 & 40 & 95 & 13 & 27 \\
\hline \multicolumn{11}{|l|}{ Turic, et al. (17) } \\
\hline \multicolumn{11}{|c|}{ Elder Meal Program Participants } \\
\hline Baty (18) & 37 & 7 & 3 & 3 & 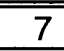 & 3 & 50 & 73 & 30 & 7 \\
\hline Baxter, et al. (19) & 42 & 12 & 30 & 2 & 23 & 24 & 61 & 59 & 21 & 41 \\
\hline Bremenstul, et al. (20) & 33 & 17 & 33 & 3 & 13 & 13 & 40 & 51 & 18 & 24 \\
\hline \multicolumn{11}{|l|}{ Coulston, et al. (21) } \\
\hline Herndon (22) & 39 & 10 & 18 & ${ }^{\star}$ & 20 & 4 & 58 & 59 & 23 & 51 \\
\hline Ponza, et al. (C) (23) & 30 & 2 & 48 & 2 & & 12 & 51 & 40 & 18 & 12 \\
\hline Ponza, et al. (HD) (23) & 34 & 4 & 58 & 1 & & 18 & 61 & 61 & 30 & 65 \\
\hline Ponza, et al. (C) (24) & 55 & 4 & 65 & 3 & & 26 & 41 & 46 & 32 & 13 \\
\hline Ponza, et al. (HD) (24) & 41 & 1 & 74 & * & & 25 & 29 & 46 & 18 & 36 \\
\hline Porter (25) & 35 & 12 & 34 & 3 & 15 & 19 & 47 & 41 & 18 & 16 \\
\hline \multicolumn{11}{|l|}{ Rosner (26) } \\
\hline \multicolumn{11}{|l|}{ Siudara, et al. (27) } \\
\hline \multicolumn{11}{|l|}{ Spangler, et al. (28) } \\
\hline \multicolumn{11}{|l|}{ Stouder, et al. (29) } \\
\hline Vailas, et al. (C) (30) & 29 & 7 & 22 & 3 & 10 & 6 & 49 & 43 & 15 & 16 \\
\hline Vailas, et al. (HD) (30) & 39 & 12 & 28 & 2 & 19 & 12 & 68 & 63 & 25 & 66 \\
\hline \multicolumn{11}{|l|}{ Weddle, et al. (31) } \\
\hline Wilson, et al. (32) & 37 & 8 & 24 & 3 & 14 & 11 & 37 & 40 & 19 & 17 \\
\hline \multicolumn{11}{|c|}{ General Community Residing Elder Population } \\
\hline Bonilla (33) & 36 & 19 & 61 & $\overline{~ \star ~}$ & $\overline{15}$ & 8 & 38 & 57 & 17 & 9 \\
\hline Garofalo, et al. (34) & 15 & 6 & 12 & 1 & 7 & 5 & 20 & 18 & 8 & 8 \\
\hline \multicolumn{11}{|l|}{ Lowry (35) } \\
\hline Melnik, et al. (36) & 49 & 6 & 31 & 5 & 39 & 14 & 63 & 49 & 22 & 2 \\
\hline Posner, et al. (6) & 35 & 12 & 35 & 4 & 12 & 8 & 42 & 34 & 20 & 18 \\
\hline Ryan, et al. (37) & 37 & 10 & 10 & 36 & 14 & 17 & 46 & 43 & 17 & 21 \\
\hline \multicolumn{11}{|l|}{ Siudara, et al. (27) } \\
\hline Spangler, et al. (38) & 40 & 9 & 23 & 4 & 10 & 6 & 32 & 33 & 17 & 6 \\
\hline Stouder, et al. (29) & & & & & & & & & & \\
\hline
\end{tabular}

${ }^{*}$ less than $0.5 \%$ 
geriatric patients" and "with minor adjustments, this tool could be helpful in screening patients in other outpatient clinics" (12).

Reiter, et al., studied 69 elder ambulatory patients at a family medical clinic; $23 \%$ of the study participants were referred to a registered dietitian for nutritional counseling after being screened (13). Three months after meeting with the dietitian, $29 \%$ of the subjects reported making dietary changes related to NSI Checklist items. In a chart review of patients 60 years and older who attended the clinic during the previous year, before implementation of the NSI Checklist screening project, only $5 \%$ had been referred to a registered dietitian for counseling. The researchers conclude that nutritional screening of elders is needed in family medicine clinics and that the NSI Checklist "use heightens physician recognition of need for nutritional counseling for the elderly" (13).

In Massachusetts, Atkinson completed a survey of 92 newly admitted home care patients residing in urban areas (14). The results of the survey were obtained through personal communication that resulted from a request for further information on a study briefly mentioned in the NSI publication "Implementing Nutrition Screening and Intervention Strategies" (4).

The Nutritional Risk Index, the NSI Checklist, an activities of daily living (ADL) assessment, and general medical history questions were the tools employed in a study by Lee, et al. (15). The 23 functionally impaired homebound elders were found to have poor nutrition knowledge as well as a diet low in total energy and fiber. The authors reported that "nutritional needs were not routinely evaluated by physicians," and patients who lived with a family member or had a 
caregiver "seemed to have better nutrition, more access to services and fewer problems to report." The authors concluded that a "targeted education program tailored to this population's cultural background and sensitive to the resources of the homebound elderly may improve nutrition by allowing for more informed food choices" (15).

In a study of home care patients by Thompson, et al., all 75 subjects were subsequently screened with the Level I Screen, and $60 \%$ of those were confirmed to be at nutritional risk (16). Of the 37 subjects who were then assessed with the Level II Screen, $100 \%$ were confirmed to be at nutritional risk. The information gathered for the meta analysis was done through personal communication resulting from a request for further information on a study briefly mentioned in the NSI publication "Implementing Nutrition Screening and Intervention Strategies" (4).

NSI Checklist scores were among the data collected during nutrition risk screening in a prospective, longitudinal nutrition intervention trial by Turic, et al. (17). Of the 81 nursing home residents surveyed, $88 \%$ who were considered at moderate or high risk using the NSI Checklist were also considered at risk using weight criteria. The results show nutritional risk as assessed by the NSI Checklist to be highly associated with risk determined by weight criteria $(p<.001)(17)$.

\section{Elder Meal Program Participants}

The majority of the studies had populations consisting of individuals in meal programs. In a study by Baty of 30 ambulatory congregate meal 
participants, $100 \%$ of the subjects were assessed with both the NSI Checklist and the Level I Screen (18). Twenty-seven subjects, or $90 \%$, were confirmed to be at nutritional risk or had major or minor indicators of poor nutritional status. The results were obtained through personal communication that resulted from a request for further information on a study briefly mentioned in the NSI publication "Implementing Nutrition Screening and Intervention Strategies" (4).

In the state of Georgia, the NSI Checklist was administered statewide to 11,817 congregate and home delivered meal participants. Baxter, et al. found that $75.1 \%$ of the subjects were at nutritional risk (19). Results also show that females $(p \leq .05)$, blacks $(p \leq .01)$, the oldest old $(p \leq .01)$ and elders residing in rural areas have the highest mean scores. The authors suggest that "future programming efforts for these groups should target socialization strategies as well as polypharmacy use and nutritional impact" (19).

Michigan also did a statewide nutrition survey. Bremenstul, et al. used a modified NSI Checklist, and sent it to 48 randomly selected congregate meal sites (20). The mean NSI Checklist score was 4.5, and scores ranged from 0-19. The authors suggest several education programs for senior dining sites. They include: "involving a pharmacist or physician to address medications as they relate to nutritional concerns, the importance of fruits and vegetables daily, the importance of milk products and calcium, suggestions on adequate food intake for weight maintenance, identifying shopping and storage ideas to encourage adequate consumption of foods, and referral to nutrition educators and dietitians 
available in the community for individuals with general and therapeutic diet questions" (20).

In a study of the nutritional status of 230 meals-on-wheels applicants, the results of the NSI Checklist and "more traditional criteria," including anthropometric, clinical, and laboratory data were compared by Coulston, et al. (21). The researchers collected data on age, weight, body mass index, calories consumed per day, protein consumed per day, triceps skinfold, mid-arm muscle circumference, and albumin and cholesterol levels. The results of both methods of screening were similar: the NSI Checklist identified $83 \%$ at high risk and the study's criteria identified $74 \%$ at high risk for "poor nutritional status." The authors conclude that the majority of older adults who apply for meals-on-wheels are at risk for poor nutritional status and "need further assessment to determine the interventions required to maximize their health, nutritional status and functional independence" (21).

Herndon studied the nutritional status of 245 participants of home delivered meals (22). Of the 176 subjects that scored three or more on the NSI Checklist, 130 were further assessed using the Level I Screen during a home visit. Sixty-eight percent were confirmed to be at nutritional risk or had major or minor indicators of poor nutritional status. One finding is that "poor diets are due more to inadequate intakes than poor choices." The author concludes that the NSI Checklist "can be cheaply and effectively used to assess nutritional risks in Meals on Wheels programs, adult day care centers, congregate feeding sites, 
senior centers, home health agencies, retirement centers, churches, or wherever the elderly are found" (22).

Congregate meal participants across the state of New York were also assessed using the NSI Checklist (25). Findings suggest that nutrition risk is significantly associated with age $(p<.05)$, race/ethnicity $(p<.05)$, and location of residence $(p<.05)$. Individuals between 60 and 74 years of age, Hispanics, Blacks, and residents of New York City were at highest risk (25).

Rosner used the NSI Checklist to assess the nutritional status of Arizona elders from seven senior nutrition sites (26). The subjects included both congregate and home delivered meal participants. "Respondents stated that the meals most often skipped are supper and then breakfast. [The] only meal consumed is the noon meal provided by the senior center(s)." Another finding was that the conditions stated as causing a change in food intake included: diabetes, cancer, heart disease, muscular dystrophy, high blood pressure, high cholesterol, and multiple sclerosis. The results were obtained through personal communication that resulted from requests for reports of state nutrition surveys for the 1995 State Nutritionist Meeting.

"Bringing Better Nutrition to Older Adults" was a project aimed at strengthening the "coordinated care for the elderly through increased communication between physicians, local retailers, caregivers, and senior center staff." Siudara, et al. used an adapted NSI Checklist, and Level I and II Screens to nutritionally assess 700 healthy elders involved in a flu shot program, 395 frail, home delivered meal participants, and a third branch of the project surveyed the 
physicians of the frail, homebound participants (27). The Nutrition Risk Program, part of "Bringing Better Nutrition to Older Adults," is a screening, assessment, and intervention program coordinated by a registered dietitian who supervises the nutrition risk screening for all home delivered meal participants. The authors found these programs to be "effective in improving the quality of life to seniors with poor nutritional health" (27).

Spangler, et al. used the NSI Checklist, geographic information system (GIS), and demographic questions to assess the nutrition risk status of Indiana elders receiving home delivered or congregate meals (28). The authors found a range of high nutrition risk level from $20.8 \%$ to $42.2 \%$ among the 16 planning and service areas surveyed. Results revealed that individuals receiving home delivered meals "had a much greater nutrition risk level" than those participating in congregate meal programs (28).

In a study of guests at a health fair and congregate and home delivered meal participants, Stouder, et al. found the top three reported problems to be: having an illness or condition which affects dietary habits, eating alone, and taking three or more medications each day (29). The percentages of individuals at high nutritional risk varied greatly among the three populations. The authors concluded that "congregate meal participants and older people attending health fairs could benefit from nutrition education focusing on nutrition risk prevention (29).

Vailas, et al., completed a statewide nutritional survey of congregate and home delivered meal participants in Wisconsin (30). The percentage of home 
delivered meal participants who indicated the presence of all NSI Checklist items, except, "I have three or more drinks of beer, liquor or wine almost every day," was significantly greater than that of congregate meal participants $(p<.05)$. The authors also found that the home delivered meal participants were significantly older than the congregate meal participants $(p<.001)$. The authors felt that "since participation in meal programs presumably reduces nutritional risk, [the] findings underscore the importance of such programs and demonstrate the need for targeted nutrition interventions to reduce nutrition risk among program participants" (30).

Weddle, et al., used the NSI Checklist to determine the nutritional risk levels of 288 congregate and 36 home delivered meal clients from three ethnically diverse populations in South Florida (31). The home delivered meal participants were at greater risk than congregate meal participants. A variety of interventions were provided to the study participants. These included group nutrition counseling sessions on diabetes, cardiovascular disease, drug/nutrient interactions, and individualized nutrition counseling (31).

In Nevada, a statewide nutrition survey of congregate and home delivered meal participants showed that "household income, ethnicity, age, and mobility" were significantly related to level of nutritional risk $(p<.05)(32)$. Wilson, et al., concluded that "the NSI was useful in identifying sub-groups of Nevada's elderly at risk for poor nutrition and guiding related educational efforts" (32). 
General Community Residing Elder Population

A study by Bonilla of two rural Texas communities used a modified NSI Checklist and was conducted as part of an objective validation of a nutrition screening instrument (33). Stepwise regression showed that the inability to buy food had the greatest effect on the variability of the NSI Checklist score. There was also a negative relationship between the NSI Checklist score and hemoglobin value $(p=.0249)$ and transformed hemoglobin value $(p=.0216)$. There was a positive relationship with glucose values $(p=.0333)$. "Based on the data collected in this study, the assessment of nutritional status by the "DETERMINE Your Nutritional Health" checklist has limited comparability to the nutritional status findings resulting from the accepted anthropometric, biochemical and clinical indicators investigated" (33).

The New Jersey NSI Project surveyed 8,670 elders at supervised sites where nutrition education programs were conducted by a dietitian, nutritionist, or dietetics intern/student (34). Findings indicate "the elderly could benefit from increased social interactions at mealtimes, attendance at nutrition sites for the elderly, referrals for food stamps and enrollment in food distribution and home delivered meal programs" (34).

Lowry used the NSI Checklist, Level I Screen, height and weight, and a demographic questionnaire to assess 106 independently living elders (35). Seventy-five percent of the subjects who were underweight were also classified at nutritional risk by the NSI Checklist. "The DETERMINE Checklist was effective as an early screening tool for nutritional risk in older adults. It can be used as an 
educational tool to alert older adults of potential health problems before malnutrition occurs" (35).

Melnik, et al., conducted a study of 49 volunteers at senior centers (36). The tools used were the NSI Checklist and a food frequency questionnaire. Correlation coefficients show that "the strongest and most consistent inverse associations [were found] between indicators of dietary adequacy and eating alone. "For elders that live alone, apathy and social isolation can lead to reduced food intake. Social interaction at meal times may help to improve dietary adequacy (36). In settings where noninstitutionalized elderly persons live or congregate, it may be possible to use the Checklist in conjunction with a rapid dietary screening tool to inform the elderly person of his or her nutritional risk and provide information about improving the diet" (36).

In a survey of 749 Medicare beneficiaries from six New England states, Posner, et al., concluded, based on the distribution of weighted scores, that about $24 \%$ of Medicare beneficiaries are at high nutritional risk (6). They also found that the three strongest predictors of dietary inadequacy were not having enough money, eating fewer than two meals a day, and eating few fruits and vegetables. Of the elders surveyed, $70.4 \%$ perceive themselves to be in good to excellent health; however, $54.7 \%$ have at least two chronic conditions, many of which could be prevented or improved with proper nutrition. "When discussed with a health professional, the Checklist provides a foundation for further nutritional problem assessment and intervention planning, as appropriate, for identified problems" (6). 
South Carolina conducted a pilot study of the NSI Checklist administered to 402 community residing elders (37). The mean NSI Checklist score was 4.3 . "Social interventions were identified as fundamental to assisting older individuals with obtaining, preparing, and eating an appropriate diet" (37).

Spangler, et al., recruited elder volunteers from the Indiana State Fair and the Indiana Black Expo to fill out the NSI Checklist and a questionnaire on demographics, participation in community food and nutrition programs, and assistance received from various sources (38). No statistical significance was found between nutritional risk level and participants and nonparticipants in community food and nutrition programs. "Professionals need to be aware of the complexities of older persons' lives and their nutrition-related problems, which were documented in this survey by the relatedness between items on the DETERMINE checklist and demographic characteristics" (38).

\section{Elderly Nutrition Program Evaluation}

Mathematica Policy Research, Inc. (MPR) conducted an evaluation of the Elderly Nutrition Program services provided under Title III and Title VI of the Older American's Act (OAA) $(23,24)$. Title III authorizes the provision of nutrition and supportive services, such as meals, nutrition education, transportation, personal and homemaker chore services, and information and referral. Title VI authorizes the same services for elderly American Indians, Alaskan Natives, and Native Hawaiians. 
As part of the of the evaluation of the Elderly Nutrition Programs, MPR screened for nutritional risk status using an instrument based on the NSI Checklist. The MPR instrument accidentally omitted one of the ten items from the NSI Checklist; "I have tooth or mouth problems that make it hard for me to eat" $(23,24)$. The research design of the evaluation involved an extensive data collection, including interviews and a multifaceted analysis approach. To collect data, Elderly Nutrition Program participants were interviewed, and a similar group of program eligible nonparticipants was also interviewed. MPR also interviewed and observed program staff and facilities including state units on aging, tribal organizations, nutrition projects and sites, and meal preparation facilities (23, 24). There were four sets of telephone surveys with administrative agencies as well as face to face surveys of program participants, eligible nonparticipants, and directors of meal sites.

Findings of the program evaluation indicated that, compared to the general population, more than twice as many Title III participants lived alone (23). Social isolation can be an important factor leading to inadequate dietary intake, so it was encouraging to see that program participants had more social contacts than do similar nonparticipants, and individuals receiving ENP meals had higher daily intakes of key nutrients than did similar nonparticipants. The ENP meals provided over $33 \%$ of the Recommended Dietary Allowances for key nutrients, and the meals were also considered nutrient dense $(23,24)$.

The Title III program evaluation revealed that about $64 \%$ of congregate meal participants and $88 \%$ of home delivered meal participants were at 
moderate to high nutritional risk (23). Title VI program evaluation findings similarly revealed that approximately $80 \%$ of participants were at moderate to high nutritional risk (24). Furthermore, it appears that the most commonly reported problem among Title III home delivered and congregate meal participants was eating alone (23). The same does not hold true for those in Title VI programs. Congregate meal participants most frequently reported having an illness or condition that has changed their eating habits, whereas the home delivered meal participants most frequently reported consuming few milk products daily (24).

\section{Nutritional Indicators and Assessments}

Anthropometrics

Anthropometric measurements are commonly used in assessing the nutritional status of many individuals, including the elderly. They consist of a number of noninvasive body measurements that can provide information on body stores of fat and muscle (39). Some of the most common anthropometric measurements include the following: height, weight, triceps skinfold (TSF), midarm circumference (MAC) and mid-arm muscle circumference (MAMC). TSF and MAC are direct measurements taken to the nearest 2 millimeters and 0.1 centimeter, respectively. MAMC is derived from TSF; the formula is as follows: $\operatorname{MAMC}(\mathrm{cm})=[0.314 \times \operatorname{TSF}(\mathrm{mm})](40)$.

Another derived anthropometric measurement is body mass index (BMI). It can be calculated from height $(m)$ and weight $(\mathrm{kg})$; the formula is: $B M I=k g / \mathrm{m}^{2}$. 
Among the elderly, a BMI greater than $27 \mathrm{~kg} / \mathrm{m}^{2}$ suggests obesity and a BMI of less than $22 \mathrm{~kg} / \mathrm{m}^{2}$ implies an increased risk of nutrient deficiencies and associated diseases. In fact, a BMI less than 22 or greater than 27 is considered a major indicator of poor nutritional status in older Americans (1).

Major indicators are generally quantifiable and include parameters that, when measured, have a specified value or degree of change implying high likelihood of poor nutritional status (1). Another major indicator of poor nutritional status in older Americans is significantly high or low weight for height. This is often defined as $20 \%$ above or below the desirable body weight for the individual, including consideration for loss of height due to vertebral collapse and deformity (1). Other major indicators include "significant and inappropriate food intake" and a "change from 'independent' to 'dependent' in two of the ADLs or one of the nutrition-related IADLs" (1).

Biochemical Parameters

Changes in an individual's biochemical indices may indicate malnutrition in and of themselves, and they may confirm or refute nutritional diagnoses based on other measures of malnutrition such as dietary and anthropometric changes (41). Although biochemical tests are commonly used to measure nutritional status, it is worth noting that there are some limitations to this type of testing in older individuals. Disease, drug use, and age-related body changes may all result in misleading biochemical measurements. 
A serum albumin level below $3.5 \mathrm{gm} / \mathrm{dl}$ is the most commonly used biochemical indicator of malnutrition. Although serum albumin has a relatively long half-life, making it slow to indicate recent changes in protein status, it usually correlates with total body protein in uncomplicated protein-calorie malnutrition and is useful in showing changes in protein status over time (41). Numerous studies have shown a correlation between low serum protein and increased morbidity and mortality. However, albumin levels are known to decrease during the acute phase reaction of certain disease states or stressors. Therefore, an elder individual under these or similar circumstances may be incorrectly diagnosed as malnourished if serum albumin is the only indicator used to determine nutritional status (42). In addition to disease, some medications as well as age-related body changes may also result in misleading measurements. Thus, many studies utilize a combination of biochemical, anthropometric, and dietary measures to determine risk or presence of malnutrition in elder populations (42 - 45).

Serum cholesterol levels are also indicators of poor nutritional status. Older individuals with cholesterol levels below $160 \mathrm{mg} / \mathrm{dl}$ may be considered candidates for nutrition support; the interventions for those individuals with levels above $240 \mathrm{mg} / \mathrm{dl}$ need nutrition education and counseling as well as possible nutrition support and physician-prescribed cholesterol lowering medications (1).

Studies have found that low serum cholesterol levels in individuals over 50 years of age are associated with poor health status and non-cardiovascular mortality $(46,47)$. In individuals over age 80 , low serum cholesterol levels have 
been associated with all-cause mortality (47). In fact, there is evidence of significant age-related trends of decreasing protective influence of HDL-C and decreasing mortality risk with an increasing LDL-C level (47).

\section{Meta Analysis}

The term meta analysis is used to describe the application of quantitative methods to the problem of combining results from different analytic studies (48, 49). It can be very useful in revealing trends underlying the varied results of studies of the same phenomenon (50). Meta analysis is probably best defined as a quasi-statistical method that applies a number of possible techniques of measurement and data analysis. It is not a single procedure, as there are no specific tests to be done; every meta analysis is different. However, there are four basic sequential steps to be completed in every meta analysis. They are as follows:

1. formulation of the question(s) to be addressed

2. enumeration of relevant prior studies

3. review and summarization of the studies, and

4. synthesis of information.

Meta analysis is a method of statistical analysis wherein the units of analysis are the results of independent studies (51). Thus, as previously stated, the statistical methods used in each meta analysis are unique. It may be best used as a tool to elicit implications for further research, clinical practice, or policy based on the consolidation of relevant research. In meta analysis, the statistical 
unit is the primary or secondary research study and its data points are the summary statistics provided by those research studies (52).

Meta analyses focusing on a single problem would seem more likely to yield clear conclusions (50). The conclusions based on a meta analysis can be stronger than those of the individual studies because pooling generally increases statistical power; and focusing on the differences between studies enables us to determine how those differences affect the conclusions and thus develop a sound plan for a composite study $(52,53)$. Thus, for the review and incorporation of results of studies using the NSI Checklist to determine elder malnutrition risk, meta analysis seems to be the appropriate tool to employ. 


\section{Chapter III}

\section{Methodology}

\section{Data Collection}

A vigorous literature search was completed to find studies for the meta analysis. The search included studies reported between 1989 and 1996 . The studies were located through computer searches (Medline, Human Nutrition [CDROM], ERIC, Psychlit), cross-referencing, communication with professionals in the field, and hand searches of journals. Also, an announcement was placed in the Gerontological Nutritionist (GN) Newsletter, a practice group of the American Dietetic Association, asking for any studies using the NSI Checklist. Other sources were reports gathered in response to requests for state surveys and other materials for the State Nutritionist Meeting that took place in Washington, DC on December 5-6, 1995. A search in the "success stories" portion of the NSI publication "Implementing Nutrition Screening and Intervention Strategies" (4) was conducted. The authors of relevant studies or surveys were contacted by phone, mail, or fax and asked to provide any available data. Finally, bibliographies of relevant articles were searched for other studies.

Several criteria were set for inclusion in the study:

1. Use of the NSI Checklist as the screening instrument.

2. Majority of subjects over the age of 65 years.

These criteria yielded 31 usable studies. At this point, the following was added as a criterion: 
3. Data available on the number or percent of subjects at high, moderate, and low risk according to the NSI Checklist scoring system.

The remaining studies were composed of the following: eleven published research articles, eight published abstracts, six manuscript drafts, five unpublished studies/surveys whose data were obtained through personal communication, and one dissertation. The personal communications resulted from contacts made resulting from the GN Newsletter announcement and "success stories" authors as described above. The studies did not necessarily report all the data we were interested in; therefore, the authors were contacted through mailings, faxes and telephone calls, to elicit more detailed information (Appendix B). In the letter requesting further data, we also asked for the state in which the study was completed, the number of subjects residing in rural and urban/suburban areas, the mean and standard deviation of the age of the subjects, the breakdown of affirmative answers to specific NSI Checklist questions, and any other information the researcher felt was important. Of the 31 studies identified, we were unable to locate or contact one author. Accordingly, the final number of studies included in the meta analysis is 30 . Due to the number of articles available for use in this analysis, the sample process was purposive. It was necessary to use all the studies that met our criteria because they were few in number.

Later in the development of the meta analysis, it was determined that information on Level I and II Screens would be useful. Therefore, the researchers were contacted again and asked for the additional information, if it 
existed. Seven studies used one or both of the Screens, and information was available from only five of those.

\section{Data Organization}

The 30 studies were divided into three major categories based on their populations: Elder Populations in Healthcare Related Systems (HS) (Table 1.1), Elder Meal Program Participants (MP) (Table 1.2), and General Community Residing Elder Population (GC) (Table 1.3). Two categories were then divided into smaller sub-categories:

Elder Populations in Healthcare Related Systems (HS)

Hospital Inpatient and Clinic Outpatient (HICO)

Long Term Care and Home Care (LTCHC)

Elder Meal Program Participants (MP)

Congregate Meal Participants (C)

Home Delivered Meal Participants (HD)

The GC category was not sub-divided.

Eight of the MP studies had subjects from both HD and $C$ populations. In each study, the two populations were analyzed separately, as independent groups. There are also two $\mathrm{N}$ values and two sets of values for the NSI levels of nutritional risk. For these reasons, the $C$ and HD populations within each study were analyzed as separate studies in the meta analysis. 


\section{Statistical Analysis}

Statistical analysis was done using the SAS and SPSS systems. First, each of the major and sub-categories was analyzed independently to determine the weighted percentage (wtp) of subjects at each of the NSI Checklist's three levels of nutritional risk: high, moderate, and low. The wtp was calculated by the following formula: $\left(\Sigma_{\mathrm{Ni} \text { riski }}\right) \div\left(\Sigma_{\mathrm{Ni}}\right)$. The next step was to compute the observed

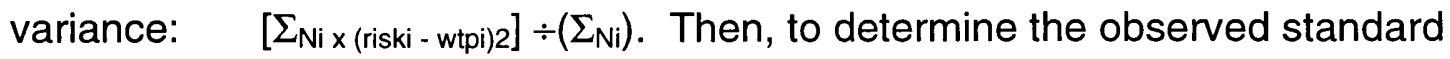
deviation $\left(S D_{\text {obs }}\right)$, the square root of the observed variance was calculated. The sampling error of proportion at risk was then computed: $\quad\left[\sum_{\text {riskix(1- riski) }}\right] \div\left(\Sigma_{\mathrm{Ni}}\right)$. The standard error was then computed by getting the square root of the sampling error of proportion of risk. Then, the residual standard deviation was calculated by taking the square root of the difference between observed variance and sampling error of proportion of risk. The residual standard deviation multiplied by 1.282 (for an $80 \%$ confidence interval) gave the margin of error (me). Finally, the confidence interval was calculated using the following formula: wtp \pm me.

These calculations were executed on all major and sub-categories at high, moderate, and low risk levels. Then, the same calculations were executed on various combinations of major and sub-categories at high, moderate, and low risk levels.

All MP studies differentiated between $C$ and HD populations with the exception of Baxter, et al. (19). For this reason, all calculations of MP were 
executed with and without Baxter, et al.. All GC calculations were executed with and without Garofalo, et al. (34), because it was not possible to determine the number of adults over 65 years in this relatively younger but very large sample size.

The major categories, sub-categories, and various combinations of categories were compared, within risk levels, with one another ( $\mathrm{z}$ test) for significance using SPSS.

The formula $\left(\Sigma_{\mathrm{Ni}} \times\right.$ wtpi $) \div\left(\Sigma_{\mathrm{Ni}}\right)$ was used to determine overall percentages of nutritional risk in each risk level: high, moderate, and low. The percentages for high and moderate risk were added together to determine overall percentage of elders at moderate to high risk.

Four studies that used the Level I or II Screen in addition to the NSI Checklist provided the numerical data needed for an analysis of predictive validity.

The predictive value of a test, or in this case a screen, is its ability to accurately measure the proportion of the population with or without the disease or condition. Positive predictive values indicate the probability that a disease or condition exists given a positive test result.

A validity coefficient was calculated as part of the test for predictive validity. The higher the validity coefficient, the greater the linear relationship of high NSI Checklist scores with results of Level I or II Screens that confirm either nutritional risk or the presence of major/minor indicators of poor nutritional status. 
Based on confirmation of nutritional risk and/or the presence of major/minor indicators of poor nutritional status, positive predictive values and validity coefficients were calculated to determine the predictive validity of the NSI Checklist in respect to Level I Screens.

The validity coefficient (vc) was calculated using the formula: (positive predictive value $-50 \%$ ) $\times 2$. Then, the standard error (se) associated with the vc was calculated: $\quad\left[1-(v c)^{2}\right] \div[\sqrt{ } N-1]$, (where $N=$ number of subjects). An alpha of .05 was chosen to determine significance, so a validity coefficient was declared significant at this level if the difference $1-(1.96 \times \mathrm{se})$ was greater than zero. If the difference of vc - $\mathrm{x}$ was greater than zero, then the results were significant at an alpha of .05 .

All five studies were pooled to obtain the predictive validity of the NSI Checklist with respect to the Level I Screen for the sample populations. First, the weighted vc (wvc) was calculated: $\quad \sum_{\mathrm{Ni} x \mathrm{vci}} \div \sum_{\mathrm{Ni}}$. Then the sample size weighted observed variance (ssov) was calculated:

$\sum_{\mathrm{Nix}(\mathrm{vci}-\mathrm{wvc})} \div \sum_{\mathrm{Ni}}$. The third step was to calculate the sampling error of validity coefficient (sev): $\quad\left[\left(1-w_{v c}^{2}\right)^{2} \div\left(N_{a v}-1\right)\right]$, where $N_{a v}$ is the average sample size. To obtain the residual variance (res), the sev was subtracted from the ssov. Then, the square root of the residual variance was obtained to get the residual standard deviation ( $\left(\mathrm{Sd}_{\mathrm{res}}\right.$ ). Finally, to obtain a $95 \%$ confidence interval, the following calculation was executed: $\quad w v c \pm 1.96\left(\mathrm{SD}_{\mathrm{res}}\right)$.

There was only one study, Thompson, et al. (16), that used both the Level I and the Level II Screens. It is the only study for which positive predictive values 
and validity coefficients were calculated for both Level I and II Screens. In this case, the predictive validity of the Level II Screen was in respect to the Level I Screen. 


\section{Chapter IV}

\section{Results}

The categories Elder Populations in Healthcare Related Systems (HS), Elder Meal Program Participants (MP), and General Community Residing Elder Population (GC) were analyzed together (total number of subjects $=66,180$ ) at each level of elder malnutrition risk as determined by the NSI Checklist: high, moderate, and low. The meta analysis results show that overall, $63 \%$ of elders are at nutritional risk; $31 \%$ are at high nutritional risk (weighted percentages ranging from $7 \%$ to $63 \%$ ), and $32 \%$ are at moderate risk (weighted percentages ranging from $20 \%$ to $63 \%$ ). Approximately $36 \%$ of elders are at low nutritional risk (weighted percentages ranging from $4 \%$ to $73 \%$ ).

The five populations of elders most likely to be at high nutritional risk are: Home Delivered Meal Participants (HD), 49.5\%; Hospital Inpatients and Clinic Outpatients (HICO), 49.1\%; the combined categories Long Term Care and Home Care (LTCHC) and HD, 49\%; and General Community Residing Elder Population (GC) [calculated without (34)] and HD, 42.7\%; and finally Elder Populations in Healthcare Related Systems (HS), 40.3\% (see Table 3.1). The category most likely to be at moderate nutritional risk is LTCHC, $45.8 \%$ (see Table 3.2). The five populations most likely to be at low nutritional risk are: GC [calculated without (34)], 51.4\%; GC [calculated without (34)] and Congregate 

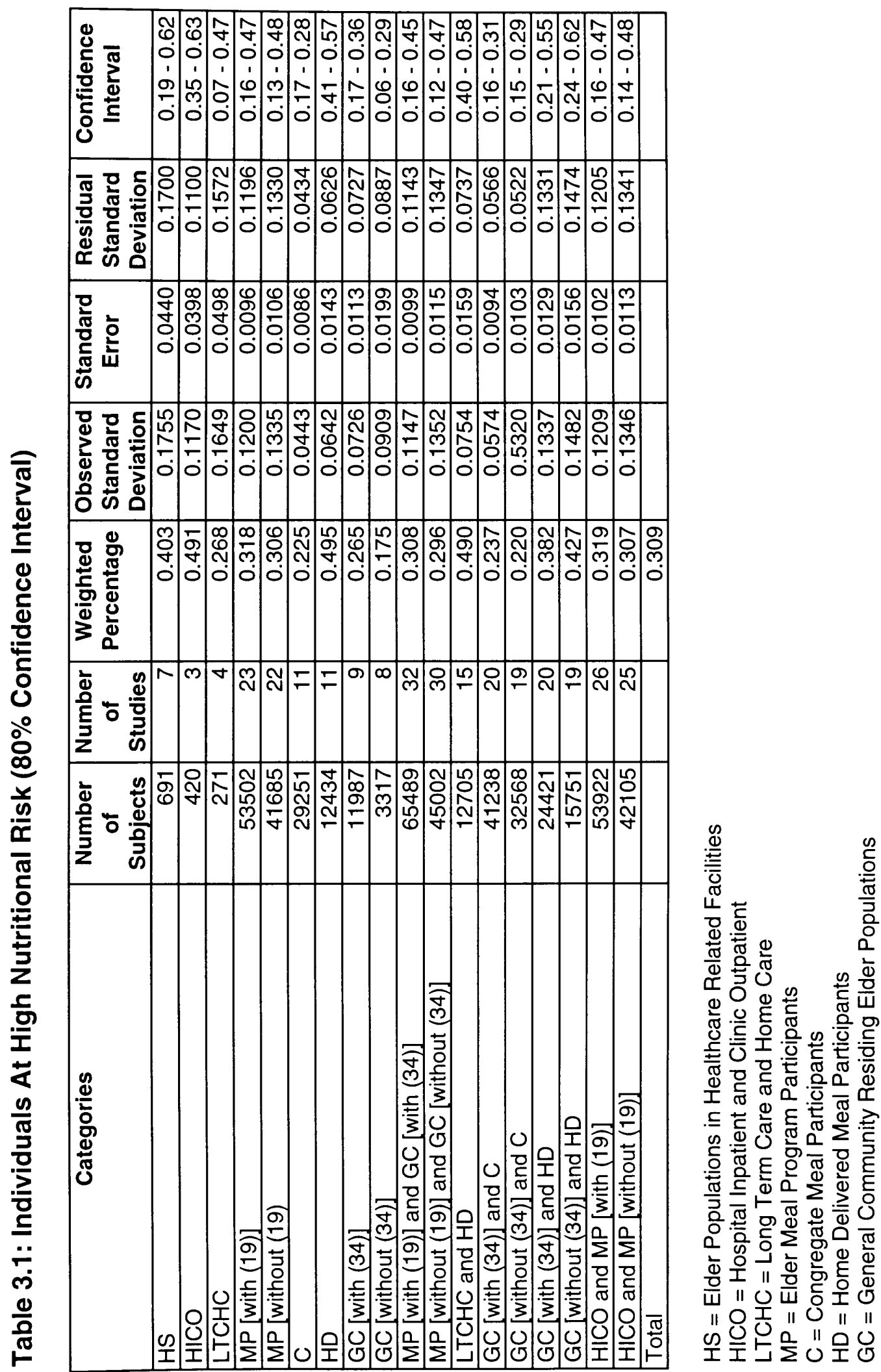

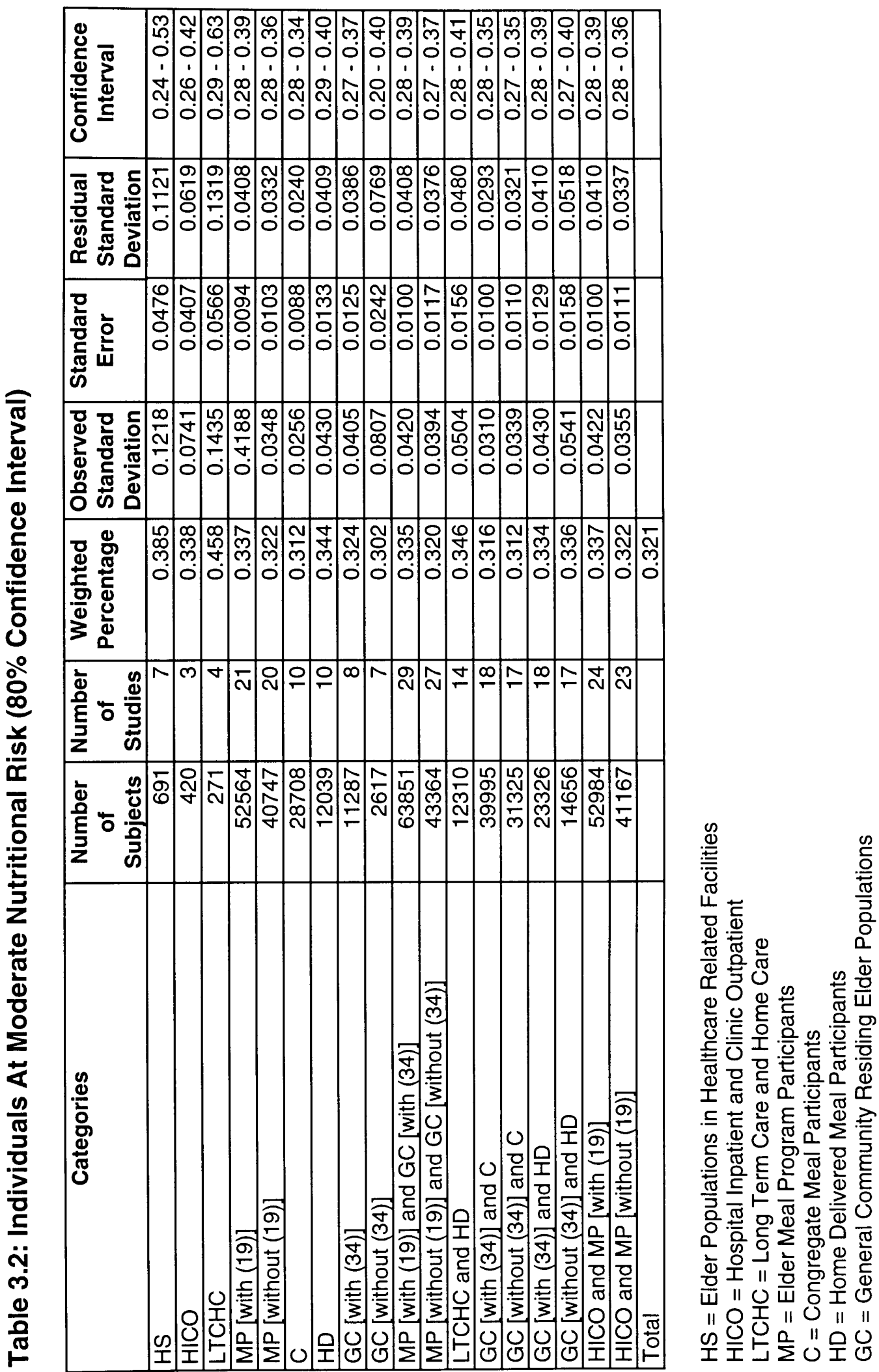
Meal Participants (C), 46.6\%; C, 46.2\%; and GC [calculated with (34)] and C, 44.5\%; and finally GC [calculated with (34)], 40.3\% (see Table 3.3).

As seen in Table 4.1, HD are significantly more at risk of malnutrition than $C$ ( $p \cong .0004), G C$ [calculated without (34)] and C ( $p \cong .0008), G C$ [calculated with (34)] and C ( $p \cong .0023), G C$ [calculated without $(34)](p \cong .0032)$, and GC [calculated with (34)] ( $p \cong .0169)$. LTCHC are significantly more at risk of malnutrition than GC [calculated with (34)] and $C(p \cong .0028), G C$ [calculated without (34)] ( $p \cong .0063), G C$ [calculated without (34)] and $C(p \cong .0065)$, and $G C$ [calculated with (34)] ( $\mathrm{p} \cong .0302)$. HICO are significantly more at risk of malnutrition than $C$ ( $p \cong .0248), G C$ [calculated without (34)] ( $p \cong .0255), G C$ [calculated without (34)] and C ( $\cong \cong .0263)$, and GC [calculated with (34)] and C $(p \cong .0403)$.

No statistical significance was found between any combination of any group, or groups of elders, at moderate nutritional risk. Table 4.2 shows statistically significant differences between elder populations at low nutritional risk. GC [calculated with (34)] and $\mathrm{C}$ are at lower risk than HICO ( $\cong .0084), H D$ ( $p \cong .0327)$, and LTCHC ( $p \cong .0362) . C$ are at lower risk than HICO ( $\mathrm{n} \cong .0016), H D$ ( $\cong .0126), L T C H C$ and HD ( $p \cong .0147)$, and HS ( $p \cong .0482)$. GC [calculated without (34)] and C are at lower risk than HICO ( $p \cong .0044), H D(p \cong .0204)$, and LTCHC $(p \cong .0230)$.

It is interesting to note that there were no statistically significant 

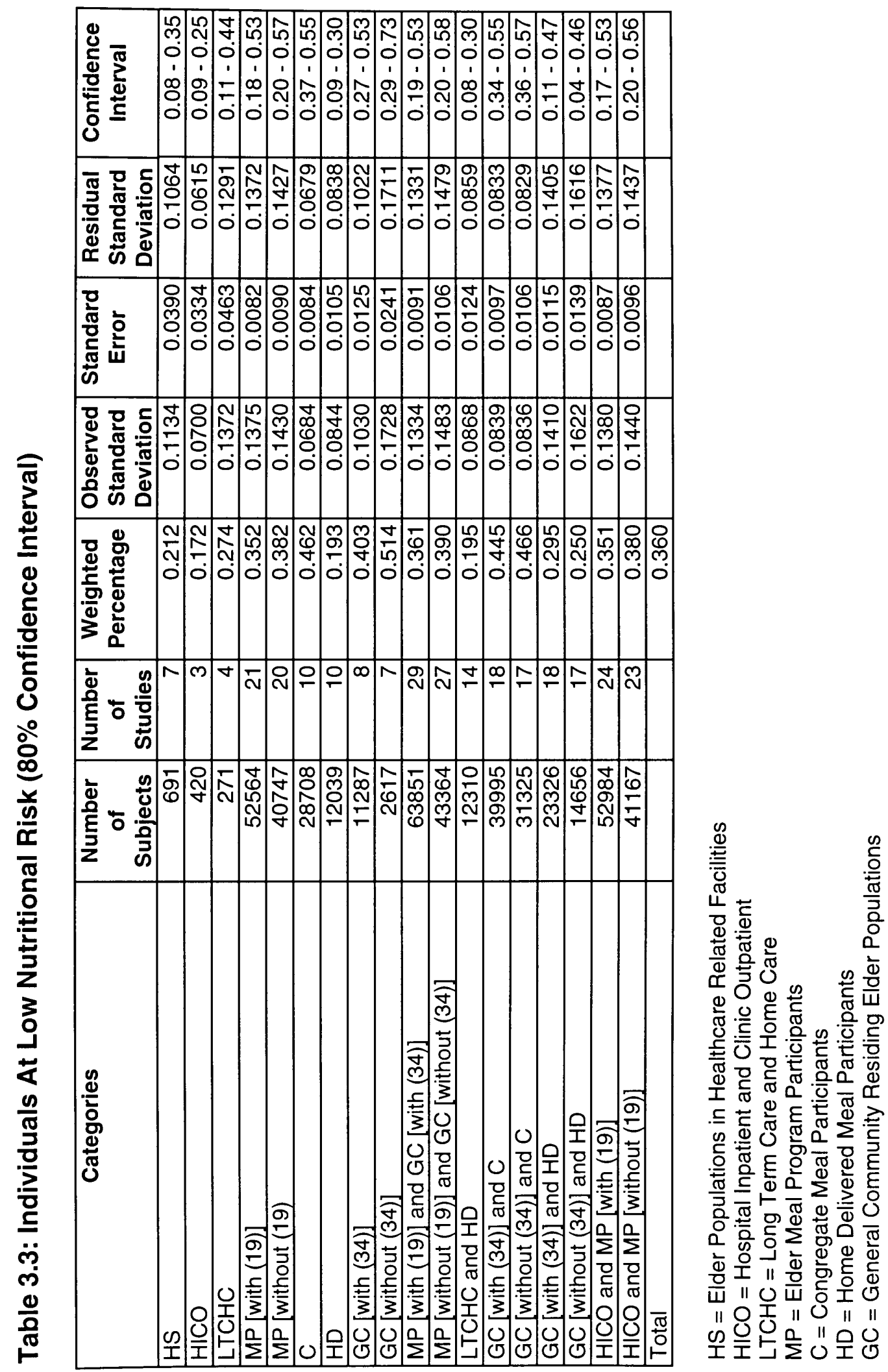


\section{Table 4.1: High Nutritional Risk: Statistically Significant Differences Between Categories}

\begin{tabular}{|l|l|l|l|}
\hline Categories Compared & Who's More at Risk & $\begin{array}{l}\text { z } \\
\text { value }\end{array}$ & $\begin{array}{l}\text { two-tailed } \\
\text { p value }\end{array}$ \\
\hline HICO vs. C & HICO & 2.24 & .0248 \\
\hline HICO vs. GC [without (34)] & HICO & 2.23 & .0255 \\
\hline HICO vs. GC [with (34)] and C & HICO & 2.05 & .0403 \\
\hline HICO vs. GC [without (34)] and C & HICO & 2.22 & .0263 \\
\hline C vs. HD & HD & 3.54 & .0004 \\
\hline HD vs. GC [with (34)] & HD & 2.39 & .0169 \\
\hline HD vs. GC [without (34)] & HD & 2.94 & .0032 \\
\hline HD vs. GC [with (34)] and C & HD & 3.05 & .0023 \\
\hline HD vs. GC [without (34)] and C & HD & 3.37 & .0008 \\
\hline LTCHC vs. GC [with (34)] & LTCHC & 2.17 & .0302 \\
\hline LTCHC vs. GC [without (34)] & LTCHC & 2.73 & .0063 \\
\hline LTCHC vs. GC [with (34)] and C & LTCHC & 2.99 & .0028 \\
\hline LTCHC vs. GC [without (34)] and C & LTCHC & 2.72 & .0065 \\
\hline
\end{tabular}

\section{Table 4.2: Low Nutritional Risk: Statistically Significant Differences Between Categories}

\begin{tabular}{|l|l|l|l|}
\hline Categories Compared & Who's Less at Risk & $\begin{array}{l}\text { z } \\
\text { value }\end{array}$ & $\begin{array}{l}\text { two-tailed p } \\
\text { value }\end{array}$ \\
\hline HCRS vs. C & C & 1.98 & .0482 \\
\hline HICO vs. C & C & 3.16 & .0016 \\
\hline HICO vs. GC [with (34)] and C & GC [with (34)] and C & 2.64 & .0084 \\
\hline HICO vs. GC [without (34)] and C & GC [without (34)] and C & 2.85 & .0044 \\
\hline C vs. HD & C & 2.49 & .0126 \\
\hline C vs. LTCHC and HD & C & 2.44 & .0147 \\
\hline HD vs. GC [with (34)] and C & GC [with (34)] and C & 2.14 & .0327 \\
\hline HD vs. GC [without (34)] and C & GC [without (34)] and C & 2.32 & .0204 \\
\hline LTCHC vs. GC [with (34)] and C & GC [with (34)] and C & 2.09 & .0362 \\
\hline LTCHC vs. GC [without (34)] and C & GC [without (34)] and C & 2.27 & .0230 \\
\hline
\end{tabular}

$\mathrm{HICO}=$ Hospital Inpatient and Clinic Outpatient

$\mathrm{C}=$ Congregate Meal Participants

$\mathrm{GC}=$ General Community Residing Elders

$H D=$ Home Delivered Meal Participants

LTCHC = Long Term Care and Home Care

HS= Elder Populations in Healthcare Related Systems 
differences, at any risk level, between MP with Baxter (19) and MP without Baxter or between GC with Garofalo (34) and GC without Garofalo. Therefore, any statistically significant difference that occurred in calculations of MP with Baxter also occurred without Baxter, and vice versa. Likewise, any statistically significant difference that occurred in calculations of GC with Garofalo also occurred without Garofalo, and vice versa. There is one exception, and that is that $\mathrm{HICO}$ are significantly more at risk of malnutrition than GC calculated without Garofalo ( $p \cong .0255$ ), but there is no significant difference between HICO and $G C$ calculated with Garofalo ( $\mathrm{n} \cong .0877)$.

Table 5.1 shows the positive predictive values of the studies that followed the NSI Checklist with a Level I Screen: three MP studies (one study differentiated between $\mathrm{C}$ and HD, giving an independent value for each) and one GC study. The values are as follows: Baty, et al., 90\% (18), Herndon, et al., 68\% (22), Weddle, et al., 74\% (C population) (31), Weddle, et al., 84\% (HD population) (31), and Thompson, et al., 60\% (16). All five studies showed statistically significant validity $(\alpha=.05)$ in the NSI Checklist's ability to positively predict nutritional risk or the presence of major/minor indicators of poor nutritional status. Pooling the five studies revealed the predictive validity to be $43 \%$ (Table 5.2). Results also show, with $95 \%$ confidence, that the true average validity coefficient of the NSI with respect to the Level I Screen for the sample populations is a value between $20 \%$ and $66 \%$. 


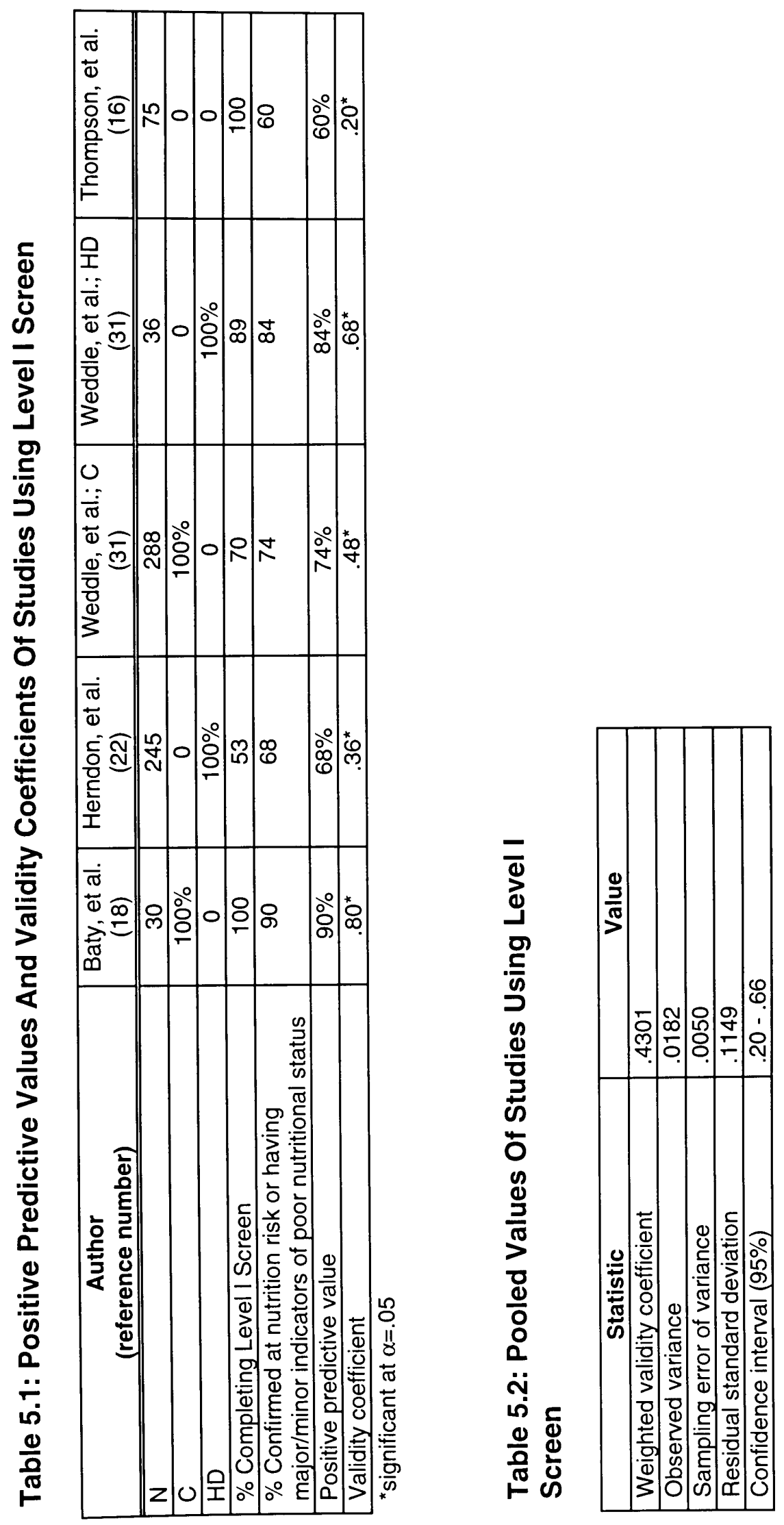


Thompson, et al. was the only study to also follow the NSI Checklist with a Level II Screen (16). The positive predictive value was $100 \%$ and the study showed statistically significant validity $(\alpha=.05)$ in the Level I Screen's ability to positively predict poor nutritional status (Table 6). It is interesting to note that in the study by Thompson, et al., although the association between the NSI Checklist scores and Level I Screen scores was the lowest, .20, of the five studies analyzed, there was a strong association between the Level I Screen scores and Level II Screen scores. 
Table 6: Positive Predictive Value And Validity Coefficient Of Study Using Level II Screen

\begin{tabular}{|l|c|}
\hline \multicolumn{1}{|c|}{ Author (reference number) } & Thompson, et al. (16) \\
\hline \hline $\mathrm{N}$ & 75 \\
\hline $\mathrm{C}$ & 0 \\
\hline $\mathrm{HD}$ & 0 \\
\hline$\%$ Completing Level II Screen & 50 \\
\hline $\begin{array}{l}\text { \% Confirmed at nutrition risk or having major/minor } \\
\text { indicators of poor nutritional status }\end{array}$ & 100 \\
\hline Positive predictive value & $100 \%$ \\
\hline Validity coefficient & $1^{\star}$ \\
\hline
\end{tabular}

*significant at $\alpha=.05$ 


\section{Chapter V}

\section{Discussion}

\section{Assumptions and Limitations}

Prior to executing the meta analysis, certain assumptions were necessary:

all studies and major categories are independent and all sub-categories are independent. Another assumption was that no individual in the General Community Residing Elder Population (GC) category was a participant in a meal program. Additionally, all percentages of risk level were rounded to the nearest whole number before any calculations were done.

There were also some limitations to the meta analysis. One was the small number of studies available to be analyzed. More studies of elder malnutrition risk using the NSI Checklist need to be done, and another meta analysis including those studies should follow. Another limitation was the availability of only four studies that followed the NSI Checklist with a Level I and/or II Screen.

This made it difficult to determine whether the NSI Checklist is a valid instrument to identify nutritional risk in various populations. Additionally, the number of subjects reported to be confirmed at nutrition risk or as having major/minor indicators of poor nutritional status was self-reported by the authors, and was based on somewhat subjective data. This may have introduced a certain degree of bias to this portion of the meta analysis. 
A limitation inherent to meta analyses is problems of heterogeneity of studies both in terms of methodology and quality. There are as many different methods as there are studies, in this case, 30. Although researchers may use similar techniques, each is essentially unique. Differences in methodology, even on the same sample, can lead to differences in results. Therefore, differences in methodology across studies introduces limitations in terms of comparability. Heterogeneity of quality can affect the comparability of studies much in the same way as heterogeneity of methods. However, these differences in methodology and quality are not so significant as to diminish the power of meta analysis, as pooling generally increases statistical power; and focusing on the differences between studies enables the determination of how those differences affect the conclusions.

\section{Extent of Elder Malnutrition}

The portion of the population most likely to be at high risk of malnutrition is Home Delivered Meal Participants (HD). Three of the four HD categories are among the top five at highest nutrition risk. The other HD category is ranked number six. Individuals who get a home delivered meal are frail, and although they are usually receiving one hot meal five days a week, it apparently is not enough. Forty-one percent of home delivered meal programs reportedly have waiting lists $(23,24)$. Elders who are at highest risk for malnutrition on waiting lists may need to be identified as highest priority to receive home delivered meals sooner than those at lower malnutrition risk. Although congregate and 
home delivered meal programs and the Food Stamp Program reach those individuals with the highest rates of food insecurity, there are a number of people who do not meet the income guidelines for food stamps or will not accept aid due to its connotation as welfare (54).

The populations least at nutritional risk are general community residing elders and congregate meal participants. These two populations, and combinations including them, occupied all of the top five positions at lowest risk. Individuals who participate in congregate meals are generally healthier than the more frail homebound who receive home delivered meals. The same holds true for the general community residing elder population. This could be one explanation for the significant differences in risk level. Although the general community residing and congregate meal participant populations are least at risk for malnutrition, action must be taken to help them to continue to age in place. Screening for malnutrition risk should be done every three to six months, and any appropriate preventive measures should be taken to maintain good nutritional status. Nutrition education would also be appropriate for these populations. Aging in place also includes making available a range of living options and services to accommodate those who have no impairments, such as private residences, adult continuing care retirement communities, assisted-living facilities, group housing, and adult day care (54).

The results indicate that the NSI Checklist is a valid screening instrument for indicating nutrition risk in individuals in meal programs, but not necessarily for community residing elders. One reason for this may be that the Elder Meal 
Program Participants (MP) are more homogeneous in level of risk as compared to the heterogeneity of the General Community Residing Elder Population (GC). However, there is no statistical evidence to support this concept. Another possible reason is that, as a whole, the GC category was among the lowest at risk; therefore, a validity coefficient of .20 for the study by Thompson, et al. (16) makes sense.

The NSI Checklist was not initially intended for use as a diagnostic tool, but rather a public awareness campaign. However, it has been increasingly used in various settings to identify malnourished persons and then to initiate appropriate interventions. 


\section{Chapter VI}

\section{Summary, Conclusions, and Recommendations}

\section{Summary}

The meta analysis results show that $63 \%$ of the 66,180 elder subjects are at nutritional risk; $31 \%$ are at high nutritional risk, and $32 \%$ are at moderate risk. The five populations of elders most likely to be at high nutritional risk are: Home Delivered Meal Participants (HD), 49.5\%; Hospital Inpatients and Clinic Outpatients (HICO), 49.1\%; the combined categories Long Term Care and Home Care (LTCHC) and HD, 49\%; and General Community Residing Elder Population (GC) [calculated without (34)] and HD, 42.7\%; and finally Elder Populations in Healthcare Related Systems (HS), $40.3 \%$. The category most likely to be at moderate nutritional risk is $\mathrm{LTCHC}, 45.8 \%$.

The five populations most likely to be at low nutritional risk are: GC [calculated without (34)], 51.4\%; GC [calculated without (34)] and Congregate Meal Participants (C), 46.6\%; C, 46.2\%; and GC [calculated with (34)] and C, 44.5\%; and finally GC [calculated with (34)], 40.3\%.

$H D$ are significantly more at risk of malnutrition than $C(p \cong .0004), G C$ [calculated without (34)] and C ( $\cong .0008), \mathrm{GC}$ [calculated with (34)] and C ( $p \cong .0023), G C$ [calculated without (34)] $(p \cong .0032)$, and GC [calculated with (34)] $(\mathrm{p} \cong .0169)$. LTCHC are significantly more at risk of malnutrition than GC [calculated with (34)] and C ( $p \cong .0028), G C$ [calculated without (34)] ( $p \cong .0063)$, 
GC [calculated without (34)] and C ( $\mathrm{p} \cong .0065)$, and GC [calculated with (34)] ( $p \cong .0302)$. HICO are significantly more at risk of malnutrition than $C(p \cong .0248)$, GC [calculated without (34)] ( $\mathrm{p} \cong .0255), \mathrm{GC}$ [calculated without (34)] and C $(p \cong .0263)$, and $G C$ [calculated with (34)] and $C$ ( $p \cong .0403)$.

The positive predictive values of the three MP studies and one GC study that followed the NSI Checklist with a Level I Screen are: Baty, et al., 90\% (18), Herndon, et al., 68\% (22), Weddle, et al., 74\% (C population) (31), Weddle, et al., 84\% (HD population) (31), and Thompson, et al., 60\% (16). All five studies showed statistically significant validity $(\alpha=.05)$ in the NSI Checklist's ability to positively predict poor nutritional status or nutritional risk necessitating further intervention. Pooling the five studies revealed the predictive validity of the NSI Checklist to be $43 \%$. Results also show, with $95 \%$ confidence, that the true average validity coefficient of the NSI Checklist with respect to the Level I Screen for the sample populations is a value between $20 \%$ and $66 \%$. The only study to follow the NSI Checklist with a Level II Screen, Thompson, et al. (16), had a positive predictive value of $100 \%$. The study showed statistically significant validity $(\alpha=.05)$ in the NSI Checklist's ability to positively predict poor nutritional

status, based on subjective and objective parameters, for the sample population.

\section{Conclusions}

With $63 \%$ of the 66,180 elders studied at moderate to high nutritional risk, much needs to be done in the way of malnutrition prevention, screening and 
assessment, and appropriate intervention. Good nutritional status is an important factor in keeping elders healthy and living at home. It makes healing and recovery of illness easier, and it helps to boost the immune system. Quality of life can also be maintained, if not improved, through good nutrition. A position statement of the American Dietetic Association "supports comprehensive food and nutrition services for older adults as an integral component of the continuum of care" (54).

Dietitians are paramount to the NSl's premise that better nutrition care leads to better health and prolonged quality of life (55). Therefore, dietitians must take the lead in nutrition screening, assessment, and appropriate intervention for older adults. As a profession, they need to encourage all healthcare providers to become familiar with the individual's nutritional needs and circumstances of each of their elder patients/clients (56).

Dietitians must also be familiar with referral systems and community based sources of aid. They should know the protocol for obtaining food stamps and participating in meal programs and other available community programs. Malnutrition is expensive, the cost of a one-day hospital stay is equivalent to one year's worth of home delivered meals $(54,57)$. Preventing an illness, disease, or condition is often cheaper than treating it. Malnutrition is no exception. It can have far-reaching implications in terms of prognosis, recovery, and quality of life. Older Americans are especially vulnerable, and preventive practices ought to be more aggressive for this population. Unfortunately, many elders do not receive nutrition counseling as a preventive measure because they would have to pay 
out-of-pocket for it. This is especially disturbing when one considers how vulnerable elders can be to the fraudulent schemes and practices that plague our society. Dietitians are the primary providers of medical nutrition therapy (57), and elders should have access to medical nutrition therapy.

There are many factors that can influence, or be influenced by nutritional status. Dietitians must understand how these factors interact so that they can be an effective part of the interdisciplinary care team. Dietitians provide services that are medically and socially unique in that "the psychosocial aspects of food and meals must be combined with the preventive/therapeutic aspects of medical nutrition therapy to achieve or maintain nutritional well-being" (54). Recognition of dietitians as an important part of the care team may be the first step in the pursuit for reimbursement. Dietitians can be undervalued in the health care system because nutrition services are not readily identifiable in terms of payment. One important way dietitians can increase accessibility, acquire professional status among third party payments systems, and increase professional recognition is to seek and support a system for reimbursement of their services (55).

\section{Recommendations}

Dietitians have a responsibility to become advocates for public policy changes affecting older Americans. For example, programs aimed at decreasing elder malnutrition risk should be expanded. "An integrated continuum of seamless, coordinated medical and supportive services facilitating movement of 
older persons among community, acute, and long term care sites is needed" (54). Dietitians can influence this type of change by using their knowledge base to effectively lobby and testify before Congress.

Resources should be more readily available among all disciplines. Medical and social service providers need to form networks whereby information can be shared and referrals made. In addition, further research is needed on elder malnutrition risk. More studies using the NSI Checklist will help document the extent of the problem.

The NSI Checklist was designed as a self-assessment tool for use by community residing elders. For validation purposes, more studies in various elder populations are needed using both the NSI Checklist, (to identify malnutrition risk level), and Level I and/or II Screens, (to confirm malnutrition risk or poor nutritional status). Prevention as well as effective nutrition interventions can save Medicare and other healthcare dollars. A cost-benefit study of nutrition screening and subsequent intervention should be done to document the impact nutrition has on health and well being of the elderly population.

Dietitians must make a concerted effort to be reimbursed for their services. They are a valuable part of the multidisciplinary care team, and should be treated as such. Reimbursement for nutrition services will make dietitian's services more widely available and a more (financially) feasible option to the elder population. 
Dietitians and other health professionals need to be aware of the risks and consequences of elder malnutrition. It can be devastating, and it can usually be prevented. 


\section{REFERENCES}

1. Incorporating Nutrition Screening and Interventions into Medical Practice: A Monograph for Physicians. Washington, D.C. The Nutrition Screening Initiative; 1994.

2. Hunter JE, Schmidt FL, Jackson GB. Meta Analysis: Cumulating Research Findings Across Studies. Beverly Hills, CA: Sage; 1982.

3. Report of Nutrition Screening 1: Toward a Common View. Washington, D.C. The Nutrition Screening Initiative; 1991.

4. Implementing Nutrition Screening and Intervention Strategies. Washington, D.C. The Nutrition Screening Initiative; 1993.

5. White JV, Dwyer JT, Posner BM, Ham RJ, Lipschitz DA, Wellman NS. Nutrition Screening Initiative: development and implementation of the public awareness checklist and screening tools. J Am Diet Assoc. 1992;92:163-167.

6. Posner BM, Jette AM, Smith KW, Miller DR. Nutrition and health risks in the elderly: The Nutrition Screening Initiative. Am J Public Health. 1993;83:972978.

7. NSI Technical Review Committee. Appropriate and effective use of the NSI Checklist and Screens. J Am Diet Assoc. 1994;94:647-648.

8. Determine Your Nutritional Health. The Nutrition Screening Initiative, 1010 Wisconsin Avenue, NW, Suite 800, Washington, D.C. 20007.

9. Nutrition Interventions Manual for Professionals Caring for Older Americans. Washington, D.C. The Nutrition Screening Initiative; 1992. 
10. White JV, Dwyer JT, Wellman NS, Blackburn GL, Barrocas A, Chernoff R, Cohen D, Lysen L, Moore S, Moyer B, Pla G, Roe D. Beyond nutrition screening: a systems approach to nutrition intervention. J Am Diet Assoc. 1993;93:405-407.

11. Barton KA, Brereton NH, Roth LS, Hooper FJ, Al-Ibrahim MS, Kinosoan B. Use of Nutrition Screening Initiative Checklist in assessing malnutrition among elderly hospitalized patients. J Am Diet Assoc. 1995;95:A-89 (Suppl).

12. O'Grady CA, Foley SP, Cooper CA. The Nutrition Screening Initiative in a VA geriatric outpatient clinic. J Am Diet Assoc. 1994;94:A-58 (Suppl).

13. Reiter SA, Lillich DW. Response to the DETERMINE Your Nutritional Health Checklist at a family medicine clinic. J Am Diet Assoc. 1995;95:A-29 (Suppl).

14. Atkinson L. Personal Communication. February 15, 1996.

15. Lee MY, Novielli KD. A nutritional assessment of homebound elderly in a physician-monitored population. J Nutr Eld. 1996;15:1-13.

16. Thompson H. Personal Communication. March 1, 1996.

17. Turic AM, Lowry KR, Craig LD. Comparison of NSI "Checklist" with weight status criteria for determining risk for malnutrition in elderly nursing home residents. J Am Diet Assoc. 1993;93:A-101 (Suppl).

18. Baty LC. Personal Communication. January 1996.

19. Baxter DH, Pang S, Reddy S. Results of the statewide administration of the Nutrition Screening Initiative Checklist State of Georgia. J Am Diet Assoc. 1994;94:A-57 (Suppl). 
20. Bremenstul K, Friend J, Murphy A. The Nutrition Screening Initiative in Michigan - 1994 Summary Report. Michigan Office of Services to the Aging and Michigan State University Extension, September 1994.

21. Coulston AM, Craig L, Voss AC. Meals-on-wheels applicants are a population at risk for poor nutritional status. J Am Diet Assoc. 1996;96:570573.

22. Herndon AS. Using the Nutrition Screening Initiative to survey the nutritional status of clients participating in a home delivered meals program. J Nutr Eldr. 1995;14:15-25.

23. Ponza M, Ohls JC, Millen BE, McCool AM, Needels KE, Rosenberg L, Chu D, Daly C, Quatramoni PA. Elderly Nutrition Program Evaluation. Final Report. Volumes I: Title III evaluation findings. Revised Draft; May 1996.

24. Ponza M, Ohls JC, Millen BE, McCool AM, Needels KE, Rosenberg L, Chu D, Daly C, Quatramoni PA. Elderly Nutrition Program Evaluation. Final Report. Volumes II: Title VI program findings. Revised Draft; May 1996.

25. Porter F. Congregate meal recipient Nutrition Screening Initiative project. Draft. New York State Office for the Aging; 1995.

26. Rosner K. Analysis of preliminary nutrition screening completed in Region V. (Personal Communication); December 8, 1995.

27. Siudara HA, Perrino D, Miller M, McManus B. Community-based senior program uses Nutrition Screening Initiative Risk Form. Top Clin Nutr. 1992;8:64-69. 
28. Spangler AA, Hannah C, Spangenberg E, Eigenbrod J. Application of geographic information system (GIS) to analyze metropolitan and nonmetropolitan distribution patterns of nutrition risk in a survey of 11891 older persons. J Am Diet Assoc. 1995;95:A-35 (Suppl).

29. Stouder ML, Spangler AA. Comparison of nutritional risk indicators and levels among a continuum of independent-dependent elderly in Northeast Indiana. 1996;96:A-57 (Suppl).

30. Vailas LI, Russo L, Nitzke SA, Rankin C. Nutritional risk in Wisconsin elderly meal program participants. Nutrition Education for the Public. 1995;15:1-4.

31. Weddle DO, Bates GM, Wellman NS. A screening and intervention program to identify nutrition needs of Title III(C) ethnically diverse elders in Dade County, Florida. J Am Diet Assoc. 1994;94:A-64(Suppl).

32. Wilson D, Benedict J. Nevada's elderly: nutrition screening, risk, and interventions. Nutr Reviews. 1996;54:S45-S47.

33. Bonilla JE. Objective validation of a nutrition screening instrument in two rural communities. Lubbock, TX: Texas Tech University; 1995. Dissertation.

34. Garofalo JA, Hynak-Hankinson MT. New Jersey's Nutrition Screening Initiative: activities and results. J Am Diet Assoc. 1995;95:1422-1424.

35. Lowry KR. Evaluation of Nutrition Screening Initiative screening tools in characterizing nutritional status of older adults. J Am Diet Assoc. 1994;94:A62 (Suppl). 
36. Melnik TA, Helferd SJ, Firmery LA, Wales KR. Screening elderly in the community: the relationship between dietary adequacy and nutritional risk. $J$ Am Diet Assoc. 1994;94:1425-1427.

37. Ryan C, Bundrick M. Nutritional screening of older South Carolinians: a pilot study. J South Carolina Med Assoc. 1995; 260-262.

38. Spangler AA, Eigenbrod JS. Field trial affirms value of DETERMINE-ing nutrition-related problems of free-living elderly. J Am Diet Assoc. 1995;95:489-490.

39. Kubena KS, McIntosh WA, Georghiades MB, Landmann WA. Anthropometry and health in the elderly. J Am Diet Assoc. 1991;91:1402-1407.

40. Zeman FJ. Clinical Nutrition and Dietetics. Second edition. New York, NY: MacMillan; 1991.

41. Screening Older Americans' Nutritional Health: Current Practices and Future Possibilities. Washington, D.C. The Nutrition Screening Initiative; 1991.

42. Lansey S, Waslien $\mathrm{C}$, Mulvihill M, Fillit $\mathrm{H}$. The role of anthropometry in the assessment of malnutrition in the hospitalized frail elderly. Gerontology. 1993;39:346-353.

43. Silver AJ, Morley JE, Strome LS, Jones D, Vickers L. Nutritional status in an academic nursing home. Journal of the American Geriatrics Society. 1988;36:487-491.

44. Mowé M, Bøhmer T, Kindt E. Reduced nutritional status in an elderly population ( $>70 \mathrm{y}$ ) is probable before disease and possibly contributes to the development of disease. Am J Clin Nutr. 1994;59:317-324. 
45. Nelson KJ, Coulston AM, Sucher KP, Tseng RY. Prevalence of malnutrition in the elderly admitted to long-term-care facilities. J Am Diet Assoc. 1993;93:459-461.

46. Goighot B, Schlienger J-L, Grunenberger F, Pradignac A, Aby M-A. Low cholesterol concentrations in free-living elderly subjects: relations with dietary intake and nutritional status. Am J Clin Nutr. 1995;62:547-553.

47. Kronmal RA, Cain KC, Ye Z, Omenn GS. Total serum cholesterol levels and mortality risk as a function of age. Arch Intern Med. 1993;153:1065-1073.

48. Hunter JE, Schmidt FL. Methods of Meta Analysis: Corrections for Error and Bias in Research Findings. Newbury Park, CA: Sage; 1990.

49. Monson ER, ed. Research: Successful Approaches. Mexico: ADA; 1992.

50. Shapiro D. Recent applications of meta analysis in clinical research. Clinical Psychology Review. 1985;5:13-34.

51. Mullen B, Rosenthal R. BASIC Meta Analysis: Procedures and Programs. New Jersey: Lawrence Erlbaum Associates; 1985.

52. Dattilo AM. Meta Analysis in Nutrition and Dietetics. In, Research: Successful Approaches. Mexico: ADA; 1992.

53. Hedges L, Olkin I. Meta Analysis: A Review and a New View. Educational Researcher. 1986;15:14-21.

54. Position of the American Dietetic Association: nutrition, aging, and the continuum of care. J Am Diet Assoc. 1996;96:1048-1052.

55. Shoaf LR, Wellman NS. The Nutrition Screening Initiative: responsibilities, opportunities, and challenges for dietitians. Top Clin Nutr. 1991;7:71-76. 
56. White JV, Ham RJ, Lipschitz DA, Dwyer JT, Wellman NS. Consensus of the Nutrition Screening Initiative: risk factors and indicators of poor nutritional status in older Americans. J Am Diet Assoc. 1991;91:783-787.

57. Position of the American Dietetic Association: cost-effectiveness of medical nutrition therapy. J Am Diet Assoc. 1995;95:88-91. 
Appendix A

DETERMINE Your Nutritional Health Checklist

Level I Screen

Level II Screen 
The Warning Signs of poor nutritional health are often overlooked. Use this checklist to find out if you or someone you know is at nutritional risk.

Read the statements below. Circle the number in the yes column for those that apply to you or someone you know. For each yes answer, score the number in the box. Total your nutritional score.
DETERMINE YOUR NUTRITIONAL HEALTH

\begin{tabular}{|l|c|}
\hline & YES \\
\hline I have an illness or condition that made me change the kind and/or amount of food I eat. & 2 \\
\hline I eat fewer than 2 meals per day. & 3 \\
\hline I eat few fruits or vegetables, or milk products. & 2 \\
\hline I have 3 or more drinks of beer, liquor or wine almost every day. & 2 \\
\hline I have tooth or mouth problems that make it hard for me to eat. & 2 \\
\hline I don't always have enough money to buy the food I need. & 4 \\
\hline I eat alone most of the time. & 1 \\
\hline I take 3 or more different prescribed or over-the-counter drugs a day. & 1 \\
\hline Without wanting to, I have lost or gained 10 pounds in the last 6 months. & 2 \\
\hline I am not always physically able to shop, cook and/or feed myself. & 2 \\
\hline & \\
\hline
\end{tabular}

\section{Total Your Nutritional Score. If it's -}

0.2

3-5

Good! Recheck your nutritional score in 6 months.

You are at moderate nutritional risk. See what can be done to improve your eating habits and lifestyle. Your office on aging, senior nutrition program, senior citizens center or health department can help. Recheck your nutritional score in 3 months.

6 or more You are at high nutritional risk. Bring this checklist the next time you see your doctor, dietitian or other qualified health or social service professional. Talk with them about any problems you may have. Ask for help to improve your nutritional health.
These materials developed and distributed by the Nutrition Screening Initiative, a project of:

AMERICAN ACADEMY OF FAMILY PHYSICIANS

THE AMERICAN DIETETIC ASSOCIATION

8f National COUNCIL ON THE AGING. INC.

Remember that waming signs suggest risk, but do not represent diagnosis of any condition. Tum the page to learn more about the Warning Signs of poor nutritional healdh. 


\section{The Nutrition Checklist is based on the Warning Signs described below. Use the word DETERMINE to remind you of the Warning Signs.}

\section{ISEASE}

Any disease, illness or chronic condition which causes you to change the way you eat, or makes it hard for you to eat, puts your nutritional health at risk. Four out of five adults have chronic diseases that are affected by diet. Confusion or memory loss that keeps getting worse is estimated to affect one out of five or more of older adults. This can make it hard to remember what, when or if you've eaten. Feeling sad or depressed, which happens to about one in eight older adults, can cause big changes in appetite, digestion, energy level, weight and well-being.

\section{EATING POORIY}

Eating too little and eating too much both lead to poor health. Eating the same foods day after day or not eating fruit, vegetables, and milk products daily will also cause poor nutritional health. One in five adults skip meals daily. Only $13 \%$ of adults eat the minimum amount of fruit and vegetables needed. One in four older adults drink too much alcohol. Many health problems become worse if you drink more than one or two alcoholic beverages per day.

\section{OOTH LOSS/ MOUTH PAIK}

A healthy mouth, teeth and gums are needed to eat. Missing, loose or rotten teeth or dentures which don't fit well or cause mouth sores make it hard to eat.

\section{CONOMIC HARDSHIP}

As many as $40 \%$ of older Americans have incomes of less than $\$ 6,000$ per year. Having less -- or choosing to spend less -- than $\$ 25-30$ per week for food makes it very hard to get the foods you need to stay healthy.

\section{ieduced social contact}

One-third of all older people live alone. Being with people daily has a positive effect on morale, well-being and eating.

\section{MULTIPLE MEDICINES}

Many older Americans must take medicines for health problems. Almost half of older Americans take multiple medicines daily. Growing old may change the way we respond to drugs. The more medicines you take, the greater the chance for side effects such as increased or decreased appetite, change in taste, constipation, weakness, drowsiness, diarrhea, nausea, and others. Vitamins or minerals when taken in large doses act like drugs and can cause harm. Alert your doctor to everything you take.

\section{NVOLUNTARY WEIGHT LOSS/GAIN}

Losing or gaining a lot of weight when you are not trying to do so is an important warning sign that must not be ignored. Being overweight or underweight also increases your chance of poor health.

\section{Needs assistance in Self Care}

Although most older people are able to eat, one of every five have trouble walking, shopping, buying and cooking food, especially as they get older.

\section{Elder years above age 80}

Most older people lead full and productive lives. But as age increases, risk of frailty and health problems increase. Checking your nutritional health regularly makes good sense. 


\section{Level 1 Screen}

\section{Body Weight}

Measure height to the nearest inch and weight to the nearest pound. Record the values below and mark them on the Body Mass Index (BMI) scale to the right. Then use a straight edge (ruler) to connect the two points and circle the spot where this straight line crosses the center line (body mass index). Record the number below.

Healthy older adults should have a BMI between 24 and 27 .

Height (in):

Weight (lbs):

Body Mass Index:

(number from center column)

Check any boxes that are true for the individual:

Has lost or gained 10 pounds (or more) in the past 6 months.

Body mass index $<24$

Body mass index $>27$

For the remaining sections, please ask the individual which of the statements (if any) is true for him or her and place a check by each that applies.

\section{NOMOGRAM FOR BODY MASS INDEX}

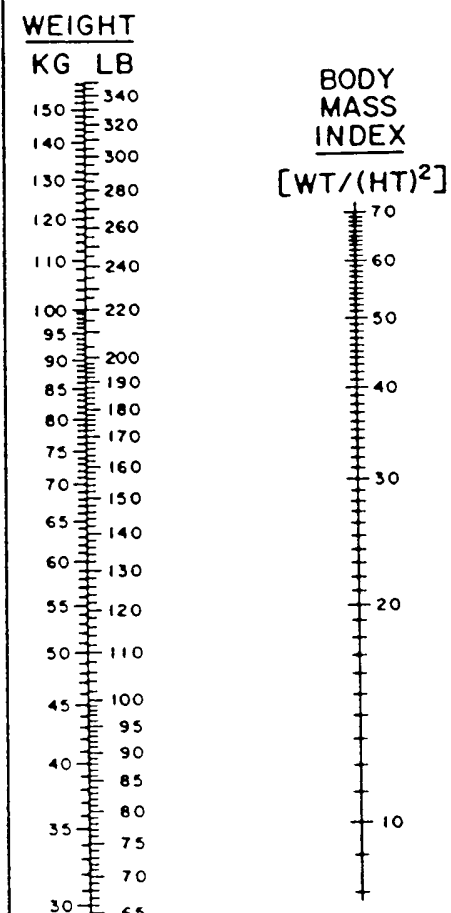

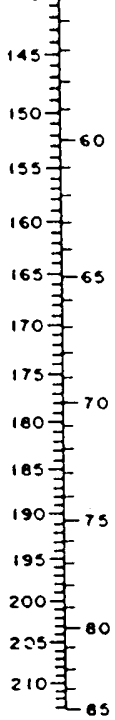

(c) George A Broy 1978

\section{Eating Habits}

Does not have enough food to eat each day

Usually eats alone

Does not eat anything on one or more days each month

Has poor appetite

Is on a special diet

Eats vegetables two or fewer times daily

Eats milk or milk products once or not at all daily

Eats fruit or drinks fruit juice once or not at all daily

Eats breads, cereals, pasta, rice, or other grains five or fewer times daily

Has difficulty chewing or swallowing

Has more than one alcoholic drink per day (if woman); more than two drinks per day (if man)

Has pain in mouth, teeth, or gums 


\section{A physician should be contacted if the individual has gained or lost 10 pounds unexpectedly or without intending to during the past 6 months. A physician should also be notified if the individual's body mass index is above 27 or below 22.}

\section{Living Environment}

Lives on an income of less than $\$ 6000$ per year (per individual in the household)

Lives alone

Is housebound

Is concerned about home security

Lives in a home with inadequate heating or cooling

Does not have a stove and/or refrigerator

Is unable or prefers not to spend money on food (<825-30 per person spent on food each week)

\author{
Functional Status \\ Usually or always needs assistance with \\ (check each that apply): \\ Bathing \\ Dressing \\ Grooming \\ Toileting \\ Eating \\ Walking or moving about \\ Traveling (outside the home) \\ Preparing food \\ Shopping for food or other necessities
}

If you have checked one or more statements on this screen, the individual you have interviewed may be at risk for poor nutritional status. Please refer this individual to the appropriate health care or social service professional in your area. For example, a dietitian should be contacted for problems with selecting, preparing, or eating a healthy diet, or a dentist if the individual experiences pain or difficulty when chewing or swallowing. Those individuals whose income, lifestyle, or functional status may endanger their nutritional and overall health should be referred to available community services: home-delivered meals, congregate meal programs, transportation services, counseling services (alcohol abuse, depression, bereavement, etc.), home health care agencies, day care programs, etc.

Please repeat this screen at least once each year--sooner if the individual has a major change in his or her health, income, immediate family (e.g., spouse dies), or functional status. 


\section{Level II Screen}

Complete the following screen by interviewing the patient directly and/or by referring to the patient chart. If you do not routinely perform all of the described tests or ask all of the listed questions, please consider including them but do not be concerned if the entire screen is not completed. Please try to conduct a minimal screen on as many older patients as possible, and please try to collect serial measurements, which are extremely valuable in monitoring nutritional status. Please refer to the manual for additional information.

\section{Anthropometrics}

Measure height to the nearest inch and weight to the nearest pound. Record the values below and mark them on the Body Mass Index (BMI) scale to the right. Then use a straight edge (paper, ruler) to connect the two points and circle the spot where this straight line crosses the center line (body mass index). Record the number below; healthy older adults should have a BMI between 24 and 27; check the appropriate box to flag an abnormally high or low value.
NOMOGRAM FOR BODY MASS INDEX

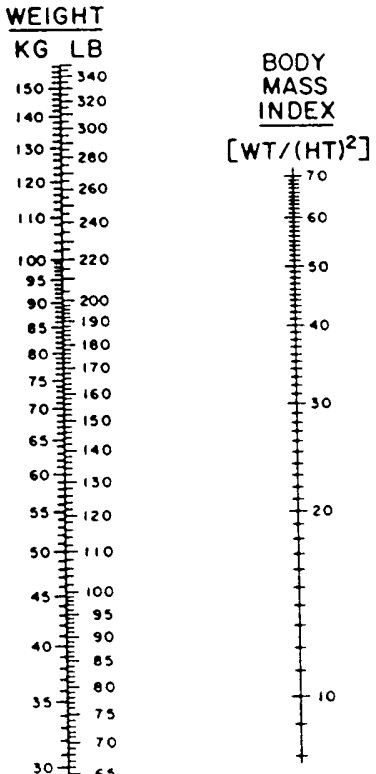

HEIGHT

CM IN<smiles>C1[SiH2]C[AsH2]1</smiles>

$130 \frac{7}{7}$

135年

140 年5s

145

150 年 60

155 年

163

180

(c) George A Bray 1978
Height (in):

Weight (lbs):

Body Mass Index

(weight/height ${ }^{2}$ ):

Please place a check by any statement regarding BMI and recent weight loss that is true for the patient.

Body mass index $<24$

Body mass index $>27$

Has lost or gained 10 pounds (or more) of body weight in the past 6 months

Record the measurement of mid-arm circumference to the nearest 0.1 centimeter and of triceps skinfold to the nearest 2 millimeters.

Mid-Arm Circumference (cm):

Triceps Skinfold (mm):

Mid-Arm Muscle Circumference (cm):

Refer to the table and check any abnormal values:

Mid-arm muscle circumference $<10$ th percentile
Triceps skinfold $<10$ th percentile

Triceps skinfold $>95$ th percentile

Note: mid-arm circumference $(\mathrm{cm})-\{0.314 \times$ triceps skinfold $(\mathrm{mm})\}=$ mid-arm muscle circumference $(\mathrm{cm})$

For the remaining sections, please place a check by any statements that are true for the patient.

\section{Laboratory Data}

Serum albumin below $3.5 \mathrm{~g} / \mathrm{dl}$

Serum cholesterol below $160 \mathrm{mg} / \mathrm{dl}$

Serum cholesterol above $240 \mathrm{mg} / \mathrm{dl}$

\section{Drug Use}

Three or more prescription drugs, OTC medications, and/or vitamin/mineral supplements daily 


\section{Clinical Features}

Presence of (check each that apply):

Problems with mouth, teeth, or gums

Difficulty chewing

Difficulty swallowing

Angular stomatitis

Glossitis

History of bone pain

History of bone fractures

Skin changes (dry, loose, nonspecific lesions, edema)

\section{Eating Habits}

Does not have enough food to eat each day

Usually eats alone

\begin{tabular}{|c|c|c|c|c|}
\hline \multirow[b]{2}{*}{ Percentile } & \multicolumn{2}{|c|}{$\mathrm{Men}$} & \multicolumn{2}{|c|}{ Women } \\
\hline & 55.65 & $65-75 y$ & $55-65 y$ & $65-75 y$ \\
\hline \multicolumn{5}{|c|}{ Arm circumference $(\mathrm{cm})$} \\
\hline $10 \mathrm{th}$ & 27.3 & 26.3 & 25.7 & 25.2 \\
\hline 50 th & 31.7 & 30.7 & 30.3 & 29.9 \\
\hline 95th & 36.9 . & 35.5 & 38.5 & 37.3 \\
\hline \multicolumn{5}{|c|}{ Arm muscle circumference (cm) } \\
\hline 10 th & 24.5 & 23.5 & 19.6 & 19.5 \\
\hline $50 \mathrm{th}$ & 27.8 & 26.8 & 22.5 & 22.5 \\
\hline 95 th & 32.0 & 30.6 & 28.0 & 27.9 \\
\hline \multicolumn{5}{|c|}{ Triceps skinfold $(\mathrm{mm})$} \\
\hline 10 th & 6 & 6 & 16 & 14 \\
\hline 50 th & 11 & 11 & 25 & 24 \\
\hline $95 \mathrm{th}$ & 22 & 22 & 38 & 36 \\
\hline
\end{tabular}

Does not eat anything on one or more days each month

Has poor appetite

Is on a special diet

Eats vegetables two or fewer times daily

Eats milk or milk products once or not at all daily

Eats fruit or drinks fruit juice once or not at all daily

Eats breads, cereals, pasta, rice, or other grains five or fewer times daily

Has more than one alcoholic drink per day (if woman); more than two drinks per day (if man)

\section{Living Environment}

Lives on an income of less than 86000 per year (per individual in the household)

Lives alone

Is housebound

Is concerned about home security

Lives in a home with inadequate heating or cooling

Does not have a stove and/or refrigerator

Is unable or prefers not to spend money on food ( $<\$ 25-30$ per person spent on food each week)

\section{Functional Status}

Usually or always needs assistance with (check each that apply):

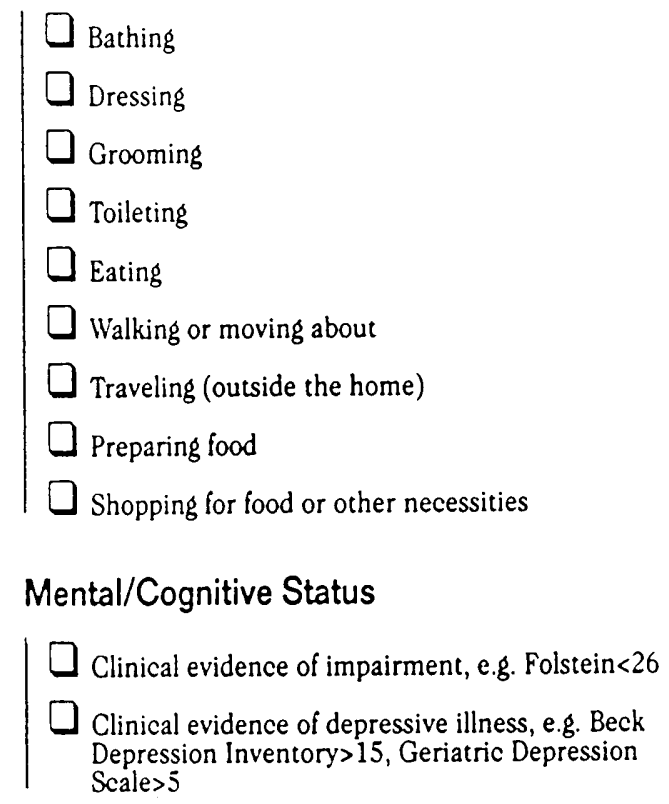

Patients in whom you have identified one or more major indicator (see pg 2) of poor nutritional status require immediate medical attention; if minor indicators are found, ensure that they are known to a health professional or to the patient's own physician. Patients who display risk factors (see pg 2) of poor nutritional status should be referred to the appropriate health care or social service professional (dietitian, nurse, dentist, case manager, etc.).

These materials developed by the Nutrition Screening Initiative. 
Appendix B

Communications with Authors 
«Title» «FirstName» «LastName», «JobTitle»

"Company"

"Address1"

"Address2"

"City», "State» «PostalCode»

Dear «Title» «LastName»,

We are working on a meta analysis manuscript of published articles on the incidence of malnutrition among America's elders. We are primarily interested in levels of malnutrition risk as determined by the Nutrition Screening Initiative Checklist and Level I and II screens, if completed.

Your study is among those we have identified in the literature. To fully include your study in our meta analysis, we are requesting further information since some is missing, probably because of space limitations imposed on your abstract. The following page lists information needed. We would greatly appreciate it if you could fax or send the information checked. We would also appreciate a copy of your complete report if available.

We thank you especially for your prompt reply. We will gladly send a copy of the published article if you so desire. Thank you again.

Sincerely,

Nancy S. Wellman, PhD, RD Professor \& Director

enclosures
Carmen Brain

Graduate Assistant 
FAX TO: Carmen Brain

FROM:

FAX:

PH:

Yes, I would like a copy of the published article.

Please respond to the checked sections.

1.

\begin{tabular}{|c|c|c|c|c|c|c|c|c|c|}
\hline \multicolumn{10}{|c|}{ NSI "DETERMINE" Checklist } \\
\hline & \multicolumn{3}{|c|}{ High Risk (> 5) } & \multicolumn{3}{|c|}{$\begin{array}{c}\text { Moderate Risk } \\
(3-5)\end{array}$} & \multicolumn{3}{|c|}{ Low Risk $(<3)$} \\
\hline & total & male & female & total & male & female & total & male & female \\
\hline Number & & & & & & & & & \\
\hline Percent & & & & & & & & & \\
\hline
\end{tabular}

2. state where your study was done:

3. sample mean age \pm standard deviation:

4. number (or percent) of sample residing in :

urban/suburban areas

rural areas

5. Other population characteristics, such as home-delivered/congregate, etc., if available. Give number and/or percentages.

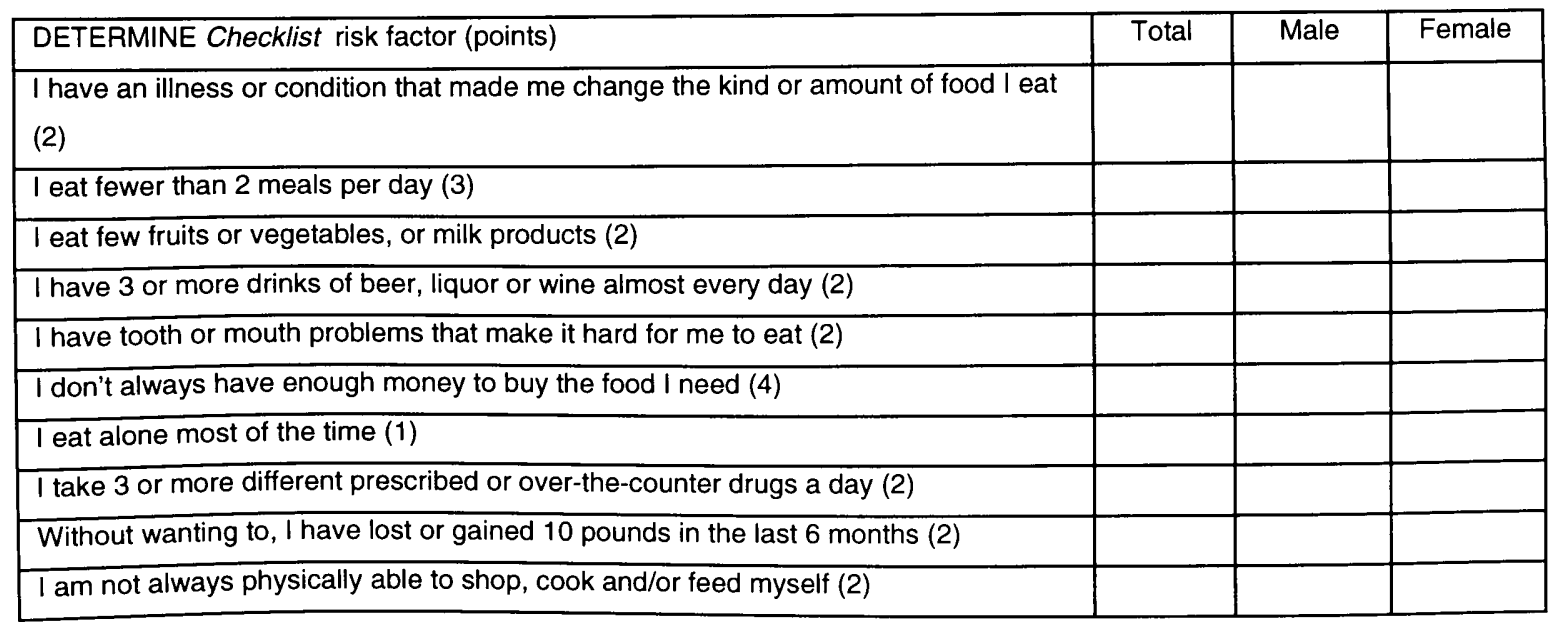


«Title» «FirstName» «LastName», «JobTitle»

«Company»

"Address 1 "

"Address2"

«City», «State» «PostalCode»

Dear «Title» «LastName»:

We are working on a meta analysis manuscript on the incidence of malnutrition among America's elders. We are primarily interested in levels of malnutrition risk as determined by the Nutrition Screening Initiative Checklist and Level I and II screens, if completed.

Your study is among those we identified in the NSI publication "Implementing Nutrition Screening and Intervention Strategies." To fully include your data in our meta analysis, we are requesting further information. The following page lists information needed. We would greatly appreciate it if you could fax or send the information checked. We would also appreciate a copy of your complete report if available.

We thank you especially for your prompt reply. We will gladly send a copy of the published article if you so desire. Thank you again.

Sincerely,

Nancy S. Wellman, PhD, RD

Carmen Brain

Professor and Director

Graduate Assistant

enclosures 
FROM:

FAX:

PH:

Please provide information for all checked sections below.

1.

\begin{tabular}{|c|l|l|l|}
\hline \multicolumn{4}{|c|}{ NSI "DETERMINE" Checklist } \\
\hline & High Risk ( $>5)$ & Moderate Risk (3-5) & Low Risk (<3) \\
\hline no. & & & \\
\hline$\%$ & & & \\
\hline
\end{tabular}

2. State where your study was done:

3. Mean age \pm standard deviation:

4. Number (or percent) residing in : urban/suburban

rural

5. Number and/or percentages of affirmative answers to each NSI Checklist item below.

\begin{tabular}{|c|c|c|}
\hline DETERMINE Checklist risk factor (points) & no. & $\%$ \\
\hline \multicolumn{3}{|c|}{$\begin{array}{l}\text { I have an illness or condition that made me change the kind or amount of food I eat } \\
\text { (2) }\end{array}$} \\
\hline \multicolumn{3}{|l|}{ I eat fewer than 2 meals per day (3) } \\
\hline \multicolumn{3}{|l|}{ I eat few fruits or vegetables, or milk products (2) } \\
\hline \multicolumn{3}{|l|}{ I have 3 or more drinks of beer, liquor or wine almost every day (2) } \\
\hline \multicolumn{3}{|l|}{ I have tooth or mouth problems that make it hard for me to eat (2) } \\
\hline \multicolumn{3}{|l|}{ I don't always have enough money to buy the food I need (4) } \\
\hline \multicolumn{3}{|l|}{ I eat alone most of the time (1) } \\
\hline \multicolumn{3}{|l|}{ I take 3 or more different prescribed or over-the-counter drugs a day (2) } \\
\hline \multicolumn{3}{|l|}{ Without wanting to, I have lost or gained 10 pounds in the last 6 months ( 2 ) } \\
\hline I am not always physically able to shop, cook and/or feed myself (2) & & \\
\hline
\end{tabular}

6. How many Checklist screened clients were subsequently assessed using
Level I (no.) $\%$
Level II
(no.) $\%$

7. How many Level I/ II clients were confirmed to be at nutritional risk or had major/ minor indicators of poor nutritional status?
Level I (no.) $\%$
Level II (no.) $\%$

8. Is Level I/ II data available? If yes, raw or computerized

\section{Yes, I would like a copy of the published article.}




\section{Wanted: NSI Screening Information}

The National Policy and Resource Center on Nutrition and Aging is trying to document the incidence of elder malnutrition nationwide. We are interested in any and all surveys, studies, and pilot data that have determined levels of malnutrition risk using the Nutrition Screening Initiative Checklist and Level I and II screens.

As our meta-analysis is starting to take shape, we would like to include your study to strengthen the case regarding the extent of this serious problem. Please fax or send us any information you have on elder malnutrition risk, be it large or small, in any setting--acute, long-term, community, special programs, etc. Call Nancy Wellman, Dian Weddle, or Carmen Brain, (graduate assistant in charge of this project), at the Center if you have questions.

National Policy and Resource Center on Nutrition and Aging

Florida International University University Park, OE 200

Miami, FL 33199

phone: (305) 348-1517

fax: (305) 348-1518

email: nutreldr@solix.fiu.edu 
«Title» «FirstName» «LastName», «JobTitle»

"Company»

«Address 1 »

"Address2"

"City», «State» «PostalCode»

Dear «Title» «LastName»:

As you know, we are working on a meta analysis manuscript of the incidence of malnutrition among America's elders. We greatly appreciate the time you took to reply to our first request for information. At this time, we are expanding our interests to include levels of malnutrition risk as determined by the Level I and Level II Screens as well as the ten item Nutrition Screening Initiative Checklist.

Your study is among those we would like to request Level and/or Level II assessment data, if it is available. The following page lists information needed. We would greatly appreciate it if you could fax or send the information checked. If you haven't had the opportunity to send us a copy of your complete report yet, we would appreciate a copy if it is available.

We thank you especially for your prompt reply. Thank you again. Sincerely,

Nancy S. Wellman, PhD, RD Carmen Brain Professor and Director Graduate Assistant

enclosures 
FAX TO: Carmen Brain FAX: 305 348-1518

PHONE: 305 348-

1517

FROM:

FAX:

PH:

Please provide information for all checked sections below.

1. How many Checklist screened clients were subsequently assessed using

Level I (no.) $\%$

Level II (no.) $\%$

2. How many Level I/ II clients were confirmed to be at nutritional risk or had major/ minor indicators of poor nutritional status?

Level I (no.) $\%$

Level II (no.) $\%$

3. Is Level I/ II data available? If yes, raw or computerized

Sorry, the Level I/II information requested is unavailable. 
«Title» «FirstName» «LastName», «JobTitle» "Company» «Address 1 " "Address2" "City», «State» «PostalCode»

Dear «Title» «LastName»:

As you may recall, we sent a letter on September 25 requesting some additional information on your study on elder malnutrition risk using the NSI Checklist. This is a gentle reminder that your study is important to us and our meta analysis. We have received replies from a number of others and are anxiously awaiting hearing from you.

If you did not receive the first letter, need more time, or have any questions, please feel free to call. Thank you in advance for your support.

Sincerely,

Nancy S. Wellman, PhD, RD Director and Professor
Carmen T. Brain

Graduate Assistant 